\title{
FORMACIÓN Y EVOLUCIÓN DEL PATRIMONIO DEL MONASTERIO DE SANTA CLARA DE ALCOCER EN LA EDAD MEDIA
}

\author{
POR \\ Pablo Martín Prieto \\ Departamento de Historia Medieval, Facultad de Geografía e Historia, \\ Universidad Complutense de Madrid
}

\section{RESUMEN}

En el presente artículo se ofrece una descripción global del patrimonio de un monasterio de Clarisas castellano en la Edad Media. El estudio de los componentes de este patrimonio monástico ayuda a entender los actores, las fuerzas y los fenómenos implicados en el proceso. Desde la misma Corona castellana, hasta simples campesinos y propietarios del común, pasando por algunas figuras relevantes de la nobleza de la época, todos ellos contribuyeron a la formación, estabilidad y sucesiva transformación del patrimonio de este monasterio hasta el final de los tiempos medievales. Su evolución también ilustra las distintas etapas en el desarrollo de la economía castellana desde el siglo XIII hasta el comienzo de la Modernidad.

PALABRAS CLAVE: Alcocer, Clarisas, monasterio, patrimonio monástico, señorío.

\section{FORMATION AND EVOLUTION OF THE HERITAGE OF THE MONASTERY OF SANTA CLARA IN THE MIDDLE AGES ALCOCER}

\begin{abstract}
This article provides a general description of the assets of a Poor Clare monastery in medieval Castile. The study of the components of the monastic heritage helps to understand the actors, forces and phenomena involved in the process. From the Castilian crown itself to simple ordinary farmers and landowners, passing by some prominent figures of the nobility of the time, they all contributed to the formation, stability and subsequent transformation of the estate of the monastery until the end of the Middle Ages. Its development also illustrates the different stages in the development of the Castilian economy since the thirteenth century until the beginning of modernity.
\end{abstract}


KEY WORDS: alcocer, Poor Clares, monastery, monastic heritage, domain.

Recibido/Received: $\quad$ 19-10-2010

Aceptado/Accepted $\quad$ 06-06-2012

Desde antiguo, el estudio del patrimonio de cenobios constituye uno de los campos de trabajo más fecundamente aprovechados para la construcción de la historia medieval, particularmente en su vertiente socio-económica. Y este protagonismo de los estudios sobre la conformación y evolución de los patrimonios de comunidades religiosas responde en todo Occidente a unos mismos patrones fijos que contribuyen a explicar su gran utilidad, tanto como la extraordinaria proliferación de estudios de esta índole.

Durante largos siglos, los monasterios fueron el ejemplo más caracterizado de métodos de gestión racional de los recursos económicos, como centros de elaboración y registro, muchas veces minucioso, de datos cuantitativos escritos.

De entre los numerosos dominios señoriales que evolucionan en Europa occidental entre la ruina del mundo carolingio y la Baja Edad Media, los gestionados por eclesiásticos son, con mucho, los mejor documentados. El funcionamiento de los archivos conventuales y el cuidado con que monjes y administradores de estos dominios anotaron y conservaron el registro de sus derechos y el residuo de su cotidiana gestión material han dado cuerpo, desde el punto de vista del investigador, a los conjuntos más completos y coherentes de información sobre estas unidades económicas en una época claramente pre-estadística.

Vamos a resumir lo esencial de la evolución del patrimonio de una comunidad religiosa afincada desde mediados del siglo XIII en la comarca alcarreña de la Alcarria Baja: el monasterio de Santa Clara de Alcocer. Ha sido considerado como uno de los puntales de la penetración mendicante en tierras de Castilla la Nueva, ${ }^{1}$ y como uno de los ejemplos más interesantes y característicos de evolución de la realidad señorial en la región. ${ }^{2}$ La fundación de este cenobio damianita ${ }^{3}$ no puede comprenderse sin aludir a la figura de doña Mayor Guillén de Guzmán, amante

1 Muñoz Fernández, A. 1994. «Las clarisas en Castilla la Nueva. Apuntes para un modelo de implantación regional de las órdenes mendicantes femeninas franciscanas (1250-1600)», en Las clarisas en España y Portugal. Actas del Congreso Internacional de Salamanca, 20-25 septiembre 1993, t. II-1: 455-472. Madrid: Archivo Ibero-Americano.

${ }^{2}$ Moxó, S. 1990. «Época de Alfonso X», en R. Menéndez Pidal (ed.), Historia de España. XIII-1. La expansión peninsular y mediterránea (1212-1350). La Corona de Castilla: 100. Madrid: Espasa-Calpe.

${ }^{3}$ Martín Prieto, P. 2002-2003. «Origen, evolución y destino del señorío creado para la descendencia de Alfonso X de Castilla y Mayor Guillén de Guzmán (1255-1312)». Temas Medievales 11: 219-240. Martín Prieto, P. 2005 [1]. «La fundación del monasterio de Santa Clara de Alcocer (1252-1260)». Hispania Sacra, 115: 227-241.

Hispania Sacra, LXV

132, julio-diciembre 2013, 563-601, ISSN: 0018-215X, doi: 10.3989/hs.2013.030 
de Alfonso X el Sabio desde antes de su ascenso al trono castellano. Cuando el Rey se persuadió de la conveniencia de apartar a su amante a un discreto segundo plano, creó para ella un señorío alcarreño con centro en Alcocer. ${ }^{4}$ Desde esta población, sita al norte del obispado de Cuenca, aquella dama emprendió, contando con la anuencia y colaboración activa de la Corona, la fundación de un monasterio de clarisas en el que residió y más tarde se hizo enterrar.

La fundación fue fruto de un esfuerzo concertado entre la familia de la propia fundadora (los Guzmán) y la Corona castellana. Desde sus comienzos, se consideró por ello «real monasterio». ${ }^{5}$ En la conformación de su patrimonio los bienes y derechos del señorío, junto con otras donaciones de la corona, desempeñaron un destacado papel. Con el tiempo este patrimonio evolucionó hacia otros fines. Describir este proceso en la documentación del periodo es el objeto de nuestro estudio.

\section{EL PUNTO DE PARTIDA: EL PATRIMONIO FUNDACIONAL (1260)}

El monasterio nace con un patrimonio, ofrecido a la institución por su fundadora, doña Mayor Guillén de Guzmán, sólidamente establecido y destinado a mantener la más estricta clausura. En su diploma fundacional, de 22 de septiembre de $1260,{ }^{6}$ se puede precisar que la procedencia de los bienes y derechos que integran en un primer momento el núcleo central del patrimonio es: bienes pertenecientes al patrimonio personal y familiar de doña Mayor y los derechos inherentes al señorío fundado en 1255 .

En la categoría de bienes propios de doña Mayor y su familia contamos, en primer lugar, una cantidad de tierras de labor en el término despoblado de la antigua aldea de San Miguel, vecina de Alcocer, hasta totalizar veinte yugadas de sembradura, de las que doña Mayor dice en el documento fundacional que representan «toda quanta heredat yo avia e compre en aquel logar cabo del monasterio». La aparición en esa frase de la expresión «yo avia» parece compadecerse con la propiedad previa, por parte de doña Mayor, de parte de esa tierra de labor como resultado de herencia o

4 1255, octubre 25, Burgos. Alfonso X concede a doña Mayor Guillén de Guzmán el señorío de las aldeas de Cifuentes, Alcocer y Viana, y de la villa de Palazuelos, así como una renta anual de 250 maravedíes situados en el portazgo de las aldeas del extremo del alfoz de Atienza. Arquivo da Torre do Tombo (Lisboa) (en adelante, ATT), Leitura Nova, Livro $1^{\circ}$ de Extras, MF 2471, fols. 192v-193v.

5 Villalba Ruiz de Toledo, F. J. 1989. «El monasterio de Santa Clara de Alcocer y su conexión con la monarquía castellana (siglos XIII-Xv)». Wad-al-.Hayara, 17: 319-324.

${ }^{6}$ 1260, septiembre 22, (Alcocer). Mayor Guillén funda el monasterio de Santa María de Alcocer, de la orden de Santa Clara, en el término de la antigua aldea de San Miguel, cerca de la villa de Alcocer, y lo dota con un primer patrimonio. Archivo Histórico Nacional (Madrid) (en adelante, AHN), Clero, carpeta 566, doc. no. 4 (en adelante, 566/4). 
concesión regia. La expresión «compre», no ofrece dificultades de interpretación: sólo cabe conjeturar hasta qué punto la adquisición por parte de doña Mayor de estas tierras estuvo relacionada directamente con la construcción del monasterio y con el propósito de vincularlas a su patrimonio por vía de donación. También en el caso de algunas de las viñas que se integran en el primer núcleo del patrimonio conventual se dice expresamente que fueron adquiridas por doña Mayor.

Otro capítulo de bienes propios de doña Mayor son las rentas de molinos. El documento fundacional de 1260 menciona la compra efectuada por doña Mayor de los molinos de Millán el Gordo y de Domingo Martín en el riachuelo llamado Riato, y de los molinos de Ferrán Pérez en el río Guadiela, así como se alude a la posible construcción, por cuenta de doña Mayor, de otras dos paradas de molinos junto al edificio monástico, en el Riato: las rentas derivadas de la explotación de todos estos ingenios pasarían a integrarse asimismo en el patrimonio fundacional del convento.

El último de los bienes «propios» que doña Mayor confía al monasterio es un olivar cuya plantación ella misma había ordenado. Son todos bienes de procedencia privada, algunos de los cuales se relacionan evidentemente con el propósito de Mayor de promover la fundación del monasterio, durante cuya construcción se adquirieron y prepararon.

Los bienes y derechos de procedencia realenga, transferidos por la corona a doña Mayor en 1255 conjuntamente con el señorío, son el monte del término de San Miguel, que una vez debió de ser comunal. Despoblada la antigua aldea de San Miguel, este monte pasó probablemente a ser propiedad de la corona, titular tradicional de los bona vacantia. Como resultado de la constitución del señorío de 1255 fue transferido a manos de doña Mayor. La renta en cereal que el concejo de Palazuelos satisfacía anualmente a la corona desde 1205, , en cuantía de 25 cahíces de trigo y 25 de cebada, renta que doña Mayor disfrutaba desde 1255 como señora del lugar, se cedió asimismo al monasterio. ${ }^{8}$ También fueron transferidos, del señorío al monasterio, la antigua participación realenga en las rentas generadas por la explotación de los molinos concejiles llamados de la Balsa en Cifuentes, ${ }^{9}$ y una participación de 200 maravedíes anuales en la renta de los portazgos de las aldeas del extremo del alfoz de Atienza, renta realenga transferida al titular del señorío en 1255 , y cuyo monto total ascendía por entonces a 250 maravedíes anuales. ${ }^{10}$

${ }^{7}$ 1205, junio 25, La Riba. Alfonso VIII otorga al concejo de Palazuelos exención de todo tributo real, a cambio del pago de una renta anual de 25 cahíces de trigo y 25 cahíces de cebada. AHN, Clero, 566/1.

${ }^{8}$ ATT, Leitura Nova, Livro $1^{\circ}$ de Extras, MF 2471, fols. 192v-193v.

${ }^{9}$ Layna Serrano, F. 1979. Historia de Cifuentes: 39-40. Guadalajara: Diputación Provincial (2a ed).

${ }^{10}$ «do et otorgo a vos, donna Mayor Guillem [...] dozientos et çinquenta maravidiis del portadgo de Atiença»: ATT, Leitura Nova, Livro $1^{\circ}$ de Extras, MF 2471, fols. 192v-193v; «E dol dozientos moravedis de renta en el portadgo del estremo de Atiença, que yo tengo en heredat de mio sennor el Rey don Alfonso, los cient e cinquaenta moravedis pora vestiario, e los cinquaenta moravedis poral enfermeria»: AHN, Clero, 566/4. 
Así pues, con esta dotación fundacional como punto de partida inicia su evolución el patrimonio monástico de las clarisas de Alcocer.

\section{Donaciones de la Familia GuZMán en VIDA DE LA FUndadora (1260-1264)}

Desde el principio, la vinculación del nuevo monasterio con la familia de su fundadora, doña Mayor Guillén de Guzmán, resulta estrechamente establecida. La fundación del monasterio de clarisas de Alcocer es tanto obra de la corona como de una familia noble cuyos destinos estarán ligados a la institución todavía durante muchos años.

En el documento fundacional de 1260, doña Mayor Guillén dispuso que el monasterio no pudiera en lo sucesivo efectuar ulteriores adquisiciones patrimoniales en tierras de su señorío-cabe interpretar que sin contar con la sanción del titular del mismo. Con ello, trataba de asegurar la independencia y la pervivencia del señorío concedido en 1255 , a la vez que fijaba la máxima expansión de las propiedades y limitaba el tamaño del convento, ordenando que nunca alimentara más de cien bocas, entre monjas y servidores. ${ }^{11}$

En los primeros años del monasterio, la fundadora doña Mayor Guillén y algunos miembros de su familia contribuyeron con nuevas donaciones a completar y redondear el primer patrimonio. Así, en octubre de 1260 don Pedro de Guzmán, adelantado mayor de Castilla, con el beneplácito y aquiescencia de sus hermanos don Nuño Guillén de Guzmán y doña Mayor Guillén, donó una participación de 50 maravedíes anuales en la renta de unos molinos suyos situados en Murcia, con preferencia sobre cualesquier otros beneficiarios de rentas en aquellos. En marzo de 1261 Alfonso X confirmaba esta donación familiar, ${ }^{12}$ de la misma forma que ya se había ocupado de confirmar la dotación fundacional de doña Mayor Guillén. ${ }^{13}$

En agosto de 1262, doña Mayor Guillén, a través de su representante Domingo Tarazona, concertó una operación de compraventa con unos vecinos de Cuenca: Loba, hija de Domingo Mínguez, muy probablemente el mismo que como escribano suscribe el documento, y su marido García Gutiérrez, vendieron a Mayor

${ }^{11}$ «E que no puedan comprar ni ganar mas desto, en ninguno de mios logares, en Alcocer, ni en Viana, ni en Cifuentes, ni en Palacihuelos. E si lo compraren ni lo ganaren, que les no vala. E pongo que sean por cuenta cient raciones, entre monias, e omes, e mugieres, e que no puedan mas seer.»: AHN, Clero, $566 / 4$.

12 1261, marzo 15, Sevilla. Alfonso X confirma e inserta una carta - con fecha 1260, octubre 20, Alcocer - en la que don Pedro de Guzmán, adelantado mayor de Castilla, hermano de doña Mayor Guillén, hace donación al monasterio de Santa Clara de Alcocer de una participación de 50 maravedíes anuales en las rentas de sus molinos de Murcia. AHN, Sellos, 55/4.

${ }^{13} 1260$, noviembre 8, Sevilla. Alfonso X confirma el privilegio - que inserta- de doña Mayor Guillén, fundando y dotando el convento de Santa Clara de Alcocer. AHN, Clero, 566/5. 
todas sus propiedades rústicas y urbanas en la ciudad y término de Cuenca, por un monto total de 800 maravedíes alfonsíes. En el documento se mencionan tierras labradas y «por labrar», árboles frutales y unas casas situadas en el barrio de San Gil, lindando con el cementerio del mismo nombre. ${ }^{14}$ En ningún momento tenemos noticia de la integración de estos bienes en el patrimonio del monasterio, pero la presencia del documento que atestigua la operación de compraventa en el archivo de la comunidad permite suponer que, ya doña Mayor o alguna de sus sucesoras, dejaron esos bienes al monasterio, que conservaría este documento en defensa de su derecho sobre los mismos.

En enero de 1264 don Pedro de Guzmán concertó una serie de operaciones de compraventa con pequeños propietarios de Alcocer, relacionadas en un mismo documento. ${ }^{15} \mathrm{El}$ resultado fue que un considerable volumen de tierras dispersas en el término de la antigua aldea de San Miguel, núcleo central y originario del patrimonio raíz de la comunidad, pasaron al patrimonio monástico, ayudando a completar y redondear la propiedad del monasterio en dicho término.

El documento especifica que las tierras las compra don Pedro de Guzmán «para el monasterio de Santa María de Alcoçer». El documento lo redacta y subscribe el escribano público de Alcocer, Domingo Núñez, «a ruego del abadesa [...] et convento». La mayoría de los pequeños propietarios que venden se están deshaciendo de toda la tierra que allí poseían. Las menciones a la cabida de las tierras no son constantes, pero van desde los 10 cahíces hasta los 50 cahíces de superficie. El exiguo precio obtenido confirma la calidad de secano de las tierras objeto de compraventa: los 50 cahíces de tierra vendidos por Domingo, hijo de Pedro Donato, sólo alcanzan un precio de 12 maravedíes, si bien cabe destacar la considerable diferencia de precios entre las distintas tierras, pues María Juan consigue 25 maravedíes por tan sólo 10 cahíces de tierra. La operación asciende a un total de 343 maravedíes y medio.

No consta quién hace entrega del dinero a cada uno, pero de la lectura del documento se desprende que don Pedro de Guzmán se encargó de toda la operación en nombre de su hermana doña Mayor. En consecuencia, en esta operación podemos ver la última contribución familiar de los Guzmán a la consolidación y aumento del patrimonio de la comunidad durante la época del señorío de Mayor. ${ }^{16}$

14 1262, agosto 26. Loba y García Gutiérrez venden a doña Mayor Guillén todos sus bienes en la ciudad y la tierra de Cuenca, por un valor total de 800 maravedíes. AHN, Clero, 566/8.

15 1264, enero 8, Alcocer. Traslado agrupado de las compraventas concertadas por don Pedro de Guzmán, adelantado mayor de Castilla, en nombre del convento de Santa Clara de Alcocer, con diversos particulares, referidas a tierras situadas en el término de la antigua aldea de San Miguel. AHN, Clero, 566/9.

${ }^{16}$ A las implicaciones sobre la coyuntura de crisis que esta crucial operación entraña nos hemos referido por extenso en: Martín Prieto, P. 2005 [2]. «Los prolegómenos de la gran crisis bajomedieval en Castilla (c. 1250-c. 1350): el caso de Alcocer». Cuadernos de Investigación Histórica 22: 291-311. 
AMPLiACión DEL PATRIMONIO BAJO El SEÑoRío de LA REINA BEATRIZ (1267-1284)

A la muerte de la fundadora, doña Mayor Guillén, quedó al frente del señorío de Alcocer su hija doña Beatriz, habida de Alfonso X, que por designio paterno se convirtió, por matrimonio con Alfonso III, en reina consorte de Portugal. ${ }^{17}$ Ignoramos si, cuando se concertó la compraventa conjunta de 1264, doña Mayor Guillén aún vivía. En cualquier caso, la presencia de su hija doña Beatriz al frente del señorío familiar está acreditada al menos desde 1267. Estrena su papel mediando en una disputa entre el concejo y el monasterio por el correcto deslinde de los términos de uno y otro. ${ }^{18}$

Con ocasión de este primer conflicto que acompañará, intermitentemente, toda la historia medieval del monasterio, la reina de Portugal se apresuró a confirmar los términos en los que su madre doña Mayor había establecido la convivencia entre el monasterio y el concejo de Alcocer y revalidó la protección del linaje Guzmán sobre la integridad de los bienes y de los derechos de la comunidad..$^{19}$

El primero de noviembre de 1272, la reina Beatriz otorgó un privilegio confirmando por extenso cada uno de los bienes y derechos concedidos por su madre doña Mayor al monasterio, a la vez que se ocupaba de ampliarlos significativamente en no pocos puntos. ${ }^{20}$ Con motivo de confirmar y clarificar lo ya concedido, doña Beatriz promueve y realiza una importante ampliación. El detalle con el que en este documento se enumeran las propiedades asignadas por doña Mayor Guillén al patrimonio nos permite conocer mejor la naturaleza y la cuantía de esos bienes y derechos.

En el documento de la reina Beatriz se especifica que las veinte yugadas de tierras de labor concedidas por doña Mayor Guillén al monasterio se situaban en el término de la antigua aldea despoblada de San Miguel, debiendo distinguirse del monte de dicho despoblado, que una vez fue comunal y realengo y que doña Mayor recibió como resultado de la constitución del señorío en 1255. Se recogen la renta de cereal del pecho de Palazuelos, las viñas

${ }^{17}$ Martín Prieto, P. 2002-2003: 227.

18 1267, julio 3, Sevilla. Alfonso X confirma un privilegio de su hija doña Beatriz, reina de Portugal - con fecha 1267, febrero 23 - en que confirma los límites de la donación original de su madre doña Mayor Guillén al convento de Alcocer, con motivo de un pleito suscitado por el concejo de la villa. AHN, Clero, 566/10.

19 1272, enero 24, Lisboa. Beatriz, reina de Portugal, confirma las posesiones del convento de Santa Clara de Alcocer y le otorga su protección. AHN, Clero, 566/11, y Archivo Municipal de Alcocer (en adelante, AMA), libro A1, fols. 187r-187v.

${ }^{20} 1272$, noviembre 1, Lisboa. Beatriz, reina de Portugal, hija de Alfonso X y doña Mayor Guillén, confirma y amplía las propiedades del convento de Santa Clara de Alcocer y lo pone bajo su especial protección. AHN, Clero, 566/12 y 566/13. 
cedidas por doña Mayor en Alcocer, las rentas de molinos en Alcocer y en Cifuentes, el olivar en el Espinar, y también la participación en la renta de portazgo de las aldeas del extremo del alfoz de Atienza, renta cuyo disfrute, anejo al señorío, había sido confirmado recientemente por Alfonso X, a petición de doña Beatriz. ${ }^{21}$

En la segunda parte del documento de noviembre de 1272, doña Beatriz expresaba su intención de completar y mejorar el patrimonio fundacional concedido por su madre al monasterio, «por mayor adereçamiento deste mi monesterio [...] et por alma de mi madre et por la mia», para lo cual procedió a realizar todo un conjunto de nuevas donaciones.

En los bienes que dona así al monasterio se hallan los restos del patrimonio familiar de los Guzmán que había heredado de su madre en Alcocer, y las adquisiciones a particulares realizadas por doña Mayor en vida, o por la misma doña Beatriz, ya fuera en vida de su madre, o con posterioridad a su fallecimiento. Como fuere, lo cierto es que el patrimonio de la comunidad se ve incrementado notablemente, pues pasa a incorporar nuevas viñas, una bodega en la población, nuevas tierras de cereales, el prado llamado de la Dehesa, una almunia y un olivar comprados por doña Beatriz en el camino de Pareja, y una renta de 500 maravedíes anuales situados en Huete. ${ }^{22}$

De la decisión y del interés que demuestra este documento se concluye que, durante el tiempo que ejerció el señorío, la reina Beatriz de Portugal se preocupó activa y personalmente de consolidar e incrementar el patrimonio, contando con el respaldo de la corona, al tiempo que continuaba lo que puso en marcha su madre. A este fin responde asimismo la merced, concedida por Alfonso X en 1274, de una renta en especie consistente en 20 cahíces anuales de sal de las salinas de Atienza. ${ }^{23}$

${ }^{21}$ 1272, septiembre 6, Burgos. Alfonso X confirma a su hija doña Beatriz, reina de Portugal, los portazgos de Alcocer, Cifuentes, Viana y Palazuelos, tal como los tuvo su madre doña Mayor Guillén. Inserto en AHN, Clero, 566/19.

22 «Et yo, por mayor adereçamiento deste mi monesterio sobredicho, et por alma de mi madre, et por la mia otrosi, do les todas las mis vinnas de Alcoçer, et la bodega, et las cubas, et las tinas, et aquel corral o es la bodega, con sus casas, et todo el mi heredamiento de pan, et el prado de la defesa; et a almuyna et ell olivar que conpre de don Johan de Don Vidal, que es carrera de Pareia; et en logar del montadgo que les tollio mi padre, do les aquellos quinientos maravedis que mi padre me da en Huepte por ende»: AHN, Clero, 566/12 y 566/13.

${ }_{23} 1274$, febrero 10, Burgos. Alfonso X concede al monasterio de Santa Clara de Alcocer 20 cahíces de sal anuales en las salinas de Atienza. Archivo de la Real Chancillería de Valladolid (en adelante, ARChVa), Pleitos Civiles, Quevedo (fenecidos), 2491 - 1, fol. 18r.

Hispania Sacra, LXV

132, julio-diciembre 2013, 563-601, ISSN: 0018-215X, doi: 10.3989/hs.2013.030 


\section{CONSOLIDACIÓN BAJO EL SEÑORíO dE LA INFANTA BLANCA (1285-1312)}

Aproximadamente desde la muerte de Alfonso X, la reina Beatriz de Portugal delegó su responsabilidad sobre la gestión del señorío de Alcocer en su hija la infanta Blanca, heredera del mismo. Durante esta etapa, hay un proceso lento de creciente desvinculación de esta infanta respecto de los destinos de su señorío y del monasterio fundado por su abuela. Este proceso culminará en la doble venta iniciada en 1311, con la que la infanta Blanca pretendía deshacerse del señorío de su abuela, a fin de concentrar su atención en otros intereses suyos situados más al norte. ${ }^{24}$

No debe sorprender, por tanto, que el periodo de la infanta Blanca haya modificado de modo poco relevante el patrimonio de las clarisas de Alcocer.

Podemos distinguir dos etapas. La primera, de relativa continuidad en la protección de la infanta Blanca, sigue el proyecto familiar con su inercia. La segunda se inicia con la designación de la infanta como abadesa del real monasterio de las Huelgas de Burgos. Desde entonces procederá a una total reordenación de sus intereses, concentrados en torno a Burgos.

En la primera etapa el monasterio consolida el patrimonio heredado, siguiendo en lo substancial las mismas direcciones apuntadas en la etapa de doña Beatriz. En 1285 Sancho IV, probablemente a petición de la comunidad, extiende un privilegio confirmando todas las mercedes y donaciones recibidas de la monarquía, del Papado y de particulares desde su fundación. ${ }^{25}$ Es una contribución, no por previsible menos notable, pues supone la continuidad de la protección de la corona, una vez consumado el relevo en su titularidad.

El mismo año, la abadesa, Urraca Alfonso, adquirió de unos particulares, en nombre de su comunidad, una participación en la propiedad y rentas generadas por el molino de Ordoño, en término de Cifuentes, por la cantidad de 50 maravedíes. ${ }^{26}$ Se trata de una operación destinada a consolidar la propiedad que el monasterio tenía ya sobre las rentas del molino, mencionado en el documento de doña Beatriz del 1 de noviembre de 1272 como incluido entre los que doña Mayor dejó al convento en el término de Cifuentes. ${ }^{27}$ Se observa, por vez primera, aun tal vez de una forma puramente nominal, que la comu-

\footnotetext{
${ }^{24}$ Martín Prieto, P. 2002-2003: 236-238.

251285 , enero 16, Atienza. Sancho IV confirma todos los privilegios, mercedes y propiedades del monasterio de Santa Clara de Alcocer. AHN, Clero, 566/14, 566/15 y 566/16.

26 1285, agosto 18, Cifuentes. Domingo Lázaro de la Fuente y su mujer María venden la novena parte de la propiedad del molino de Ordoño a Urraca Alfonso, abadesa del monasterio de Santa Clara de Alcocer, por cincuenta maravedíes. AHN, Clero, 566/17.

${ }^{27}$ AHN, Clero, 566/12 y 566/13.
} 
nidad tiene la iniciativa en el incremento del patrimonio. Hay que subrayar el hecho significativo de que esta decisión, explicable dentro de una irreprochable lógica económica, chocaba con la disposición establecida por la fundadora para que la comunidad nunca pudiera adquirir más bienes o derechos en los lugares de su señorío. ${ }^{28}$

El 21 de junio de 1291, Teresa Domínguez, llamada la Gallega, que fue criada de doña Mayor Guillén, de su hija doña Beatriz y de su nieta la infanta Blanca, otorga testamento. En él deja todos sus bienes muebles y raíces, localizados principalmente en el término de Alcocer, al monasterio..$^{29}$ Se relacionan esos bienes, de forma genérica, especificando tan sólo que se trata de casas, viñas, huertas y cubas. En la primera parte, Teresa Domínguez efectúa una deditio de sí misma a la comunidad, esto es, se confía, como anciana que ya es, al cuidado de la comunidad. Es muy probable que hubiera ingresado en la comunidad muy joven, como criada de doña Mayor, casi en el momento de la fundación, y que en él hubiera pasado casi toda su vida. En cuanto al origen de los bienes, cabe pensar que le hubieran sido cedidos en vida por doña Mayor Guillén, o por doña Beatriz, su sucesora y heredera. De esta forma, algunos de los que una vez fueron bienes de doña Mayor llegarían a integrarse en el patrimonio monástico en una fecha bastante posterior a su fallecimiento, por esta vía indirecta.

La primera de las escasas intervenciones directas de la infanta Blanca es de 1293, con motivo de un pleito entre el concejo y el monasterio a cuenta de un deslinde de sus respectivos términos. Es una nueva edición del secular conflicto que se mantendrá latente, pero constante, durante toda la existencia de la comunidad. ${ }^{30} \mathrm{La}$ infanta Blanca declina resolver el pleito como señora de Alcocer, y cede su papel arbitral al obispo de Cuenca.

Sabemos que el pleito lo causó una probable ocupación ilegal de tierras del monasterio por parte del concejo o de los vecinos, ya que su origen fue una demanda de las monjas, como se desprende del hecho de que el obispo ordenase al concejo que respondiera «a la demanda que el abadesa y el convento [...] fiziere contra vos». Al parecer, siguió sin resolverse satisfactoriamente, pues de forma intermitente se repitieron en lo sucesivo las reclamaciones del concejo; éstas rebasarán los límites convencionales de la Edad Media, sin que

${ }^{28}$ Cfr. nota 10.

29 1291, junio 21, [Alcocer]. Teresa Domínguez la Gallega, criada de doña Mayor Guillén, dona al monasterio de Santa Clara de Alcocer todas sus propiedades: casas, viñas, huertas, cubas, dentro y fuera del término de Alcocer. AHN, Clero, 566/18.

${ }^{30}$ Carta de la infanta Blanca al obispo Gonzalo de Cuenca, 18 de junio de 1293 (AHN, Clero, libro 4140, fol. 27v); carta de la infanta Blanca al concejo de Alcocer, 18 de junio de 1293 (AHN, Clero, libro 4140, fols. 26r-26v); y carta del obispo Gonzalo de Cuenca al concejo de Alcocer, 1 de julio de 1293 (AHN, Clero, libro 4140, fols. 26v-27v). 
exista constancia documental de cualquier indicio de alteración en los límites de las tierras del convento, tal como le fueron primeramente asignadas por doña Mayor Guillén.

En la segunda etapa, iniciada en 1295 con el nombramiento de la infanta Blanca como señora de las Huelgas, ${ }^{31}$ la comunidad de Alcocer, poco menos que abandonada a su suerte por el desinterés y la pasividad de la nieta de la fundadora, se hace cargo por sí misma de la gestión del patrimonio y toma algunas decisiones importantes. Comienza una política económica propia y autónoma, orientada a la más racional gestión de los bienes patrimoniales, excelente preparación para los periodos sucesivos, en los que la autonomía efectiva de la comunidad respecto de los sucesivos señores de la villa de Alcocer quedará definitivamente establecida.

El desinterés de la infanta Blanca se aprecia en detalles como el siguiente: hasta 1295 no se había ocupado de pedir y obtener de Sancho IV la confirmación de la concesión de la renta de portazgo de los lugares de Alcocer, Cifuentes, Viana, Palazuelos, Aceñón y Val de San García. Esta renta fue, originariamente, vinculada al señorío por Alfonso X en 1255, bajo el marbete genérico de las «aldeas del extremo del alfoz de Atienza». En 1272 el monarca confirmó esa donación en beneficio de doña Beatriz, redefiniéndola en los términos más arriba expresados. De esta última concesión, la infanta Blanca solicita y obtiene confirmación de Sancho IV en 1295. ${ }^{32}$ La confirmación afecta al monasterio, ya que la renta de 200 maravedíes que recibía anualmente desde la dotación fundacional de doña Mayor Guillén es una participación en esta renta de portazgos.

Como consecuencia del creciente margen para la autonomía que la ausencia de la infanta Blanca le permite, la comunidad, dirigida ahora por una abadesa enérgica, de indudable procedencia nobiliaria, Mencía Pérez Carrillo, comienza a tomar sus propias decisiones para la gestión del patrimonio. En 1299 el monasterio acuerda con Pedro Vicente, clérigo de la infanta Blanca, una permuta de unos bienes. ${ }^{33}$ Cede al monasterio dos casas de molinos situadas en el Riato que atravesaba el término de la antigua aldea de San Miguel, llamadas de Donato y de Aparicio Martínez por sus anteriores dueños; una tierra aneja a los molinos,

31 Así la designó, en su lecho de muerte, el rey Sancho IV: Sánchez Moguel, A. 1893. «Doña Blanca de Portugal». Boletín de la Real Academia de la Historia 23: 538.

32 1295, enero 3, Alcalá de Henares. Sancho IV confirma a su sobrina la infanta Blanca de Portugal un privilegio de Alfonso X - con fecha 1272, septiembre 6, Burgos-en el que concede a su madre, la reina Beatriz de Portugal, el portazgo de los lugares de Alcocer, Cifuentes, Viana y Palazuelos, tal como lo tuvo doña Mayor Guillén. AHN, Clero, 566/19.

33 1299, diciembre 10, Burgos. Pedro Vicente, clérigo de la infanta doña Blanca, señora de las Huelgas, cambia con Mencía Pérez Carrillo, abadesa del convento de Santa Clara de Alcocer, una serie de bienes en Alcocer, por todo lo que el convento tenía en Quintana de los Cojos, alfoz de Burgos. AHN, Sellos, 55/14. 
que lindaba con tierras del monasterio, el camino de Cuenca y el río; una huerta en el paraje llamado del Palomar, también lindando con terrenos del monasterio; otra tierra vecina a esta. Efectúa además un importante pago en moneda que asciende a 3000 maravedíes. A cambio, recibe de las monjas «todo quanto [ellas] an en Quintana de los Coxos, que es alhoz de Burgos». La cicatería de esta última mención nos impide toda conjetura sobre la naturaleza y el origen de los bienes que la comunidad pudiera poseer en la aldea burgalesa.

En todo caso, la abundancia y cuantía de los bienes que Pedro Vicente aporta como contraprestación para hacerse con el lote cedido por el monasterio, indica a las claras su importancia. Sin duda una laguna en la documentación conservada por el convento impide arrojar luz sobre las propiedades burgalesas de la comunidad. A cambio, contamos con una relación detallada del conjunto de bienes aportados por Pedro Vicente, bienes que pasarán al patrimonio del monasterio.

La intención de la operación es, de una parte, facilitar que la comunidad amplíe sus propiedades en Alcocer, haciéndose con el control de dos molinos, dos tierras y una huerta que lindaban con sus propiedades, redondeando y completando así sus intereses en las zonas referidas, al tiempo que se deshacía de un conjunto indeterminado de bienes cuya lejanía dificultaba en la práctica su gestión. Por añadidura, cabe suponer que Pedro Vicente, clérigo de doña Blanca, actuaba en la operación como representante suyo, y dando otro paso más hacia la definitiva desvinculación de la infanta respecto de Alcocer.

Ya en 1301, la misma abadesa Mencía Pérez Carrillo tomó una decisión sobre la explotación futura de algunos de los bienes adquiridos en la anterior permuta. Así, otorgó los molinos y el batán de Donato, con su tierra aneja, en arrendamiento, a Juan García, carnicero de Alcocer, por un periodo de dos años, a cambio de una renta anual de 10 cahíces de trigo y otros 10 de centeno y cebada mezclados. ${ }^{34}$ Con esta decisión, y haciendo uso de la creciente autonomía para la gestión de su patrimonio, la comunidad iniciaba una política de aprovechamiento indirecto de sus ingenios hidráulicos, que irá a más en la siguiente etapa.

Hasta la tardía fecha de 1309 la infanta Blanca no se ocupó de otorgar al monasterio, en nombre propio, una confirmación expresa de todas las donaciones y mercedes recibidas de sus predecesoras en el señorío de Alcocer. ${ }^{35}$

En esta merced puede entreverse un primer indicio de su voluntad de desprenderse del señorío, decisión que tomaría dos años más tarde. Justo antes

34 1301, junio 25, Alcocer. El monasterio de Santa Clara de Alcocer cede en arrendamiento los molinos del río Guadiela a Juan García, carnicero de Alcocer, por dos años, a cambio de una renta anual de 20 cahíces de cereal y de hacerse cargo de unas reparaciones en ellos. AHN, Clero, 567/2.

35 1309, mayo 1, Toledo. La infanta Blanca de Portugal otorga al monasterio de Santa Clara de Alcocer confirmación general de sus privilegios y derechos. AHN, Clero, 567/3.

Hispania Sacra, LXV

132, julio-diciembre 2013, 563-601, ISSN: 0018-215X, doi: 10.3989/hs.2013.030 
de abordar la venta del señorío, en julio de 1311, la infanta completó esos preparativos otorgando al monasterio un documento, en virtud del cual le concedía su plena y formal autorización para que la comunidad pudiera en adelante ganar y adquirir bienes y derechos en cualesquiera lugares del señorío, derogando así «cartas [...] de [...] sennoras que ante de mi fueron de la dicha tierra», clara alusión a la prohibición al respecto impuesta en su día por su abuela doña Mayor Guillén. ${ }^{36}$

Es una decisión muy significativa. Hemos comprobado el escaso vigor que en la práctica había tenido esa prohibición de doña Mayor: el patrimonio monástico del convento siguió aumentando nutriéndose de bienes radicados en Alcocer y Cifuentes. Hasta este momento, el apoyo de las sucesivas titulares del señorío a estas nuevas adquisiciones parecía haber bastado para evitar la prohibición de la fundadora. Sin embargo, desde el momento en que la infanta Blanca previó vender el señorío, debía dejar el control sobre el patrimonio del convento que oficialmente le correspondía como señora de la villa y heredera de la fundadora.

Fue necesario en consecuencia proceder a la derogación formal y expresa de una cláusula que de iure entorpecía las posibilidades de expansión del patrimonio, y cuyo cumplimiento habría podido ser exigido por los sucesivos señores de la villa, ajenos a la tradición familiar que tácitamente venía permitiendo la apropiación por parte de la comunidad de nuevos bienes y derechos en los lugares del señorío. Derogada expresamente esta limitación, nada impediría que el monasterio pudiera continuar aumentando su patrimonio en Alcocer o en otros lugares del señorío. Fue una previsión inteligente, destinada a dejar expedito el camino para ulteriores incorporaciones patrimoniales una vez que, quebrada en lo esencial la vinculación del convento con los destinos de la dinastía de la fundadora, la comunidad hubo de emprender, de forma más activa, una política propia de gestión y adquisiciones.

Amén de las ya mencionadas, el patrimonio monástico no habría experimentado variación alguna durante el tiempo en que la infanta Blanca fue señora de Alcocer, de no haber sido por una generosa donación realizada por Fernando IV en la Navidad de $1311 .{ }^{37}$ Era una renta anual de hasta 2000 maravedíes situados en los derechos y tributos que el concejo de Escamilla debía a la corona. La renta, constituida por los impuestos de martiniega, portazgo, yantar, servicios y fonsadera, ya había sido enajenada al realengo, y hasta 1311 la venía disfrutando

36 1311, julio 3, Valladolid. La infanta Blanca faculta al monasterio de Santa Clara de Alcocer para que adquiera y posea sin restricciones cualesquiera bienes raíces en todos los lugares de su señorío, exentos de todo tributo señorial. AMA, libro A1, fols. 185r y 185v.

37 1311, diciembre 25, Valladolid. Fernando IV concede al monasterio de Santa Clara de Alcocer una participación anual de hasta 2000 maravedíes en las rentas y derechos que la corona recibía en Escamilla. AHN, Clero, 567/4. 
un noble, Fernando Sánchez de Velasco; a partir de ese año, la renta fue transferida al monasterio de Alcocer, sumando un ingreso adicional de hasta 2000 maravedíes anuales.

\section{LA INDEPENDENCIA ECONÓMICA DE LA COMUNIDAD (1317-1337)}

A partir del momento en que la infanta Blanca se deshizo de sus derechos al señorío de la villa de Alcocer, la comunidad clarisa asumió un protagonismo creciente en la gestión autónoma de su patrimonio. Los nuevos señores de Alcocer nunca alcanzaron a cubrir el vacío que, en la protección del convento, había dejado la dinastía de los Guzmán.

Cuando ya la infanta Blanca se hallaba desvinculada de los destinos de Alcocer, en 1321 incluyó en su testamento una manda dotando a las clarisas de la villa con una renta anual de 2000 maravedíes. ${ }^{38}$ Fue la donación más importante a lo largo de toda esta nueva etapa, inaugurada con la entrada del infante don Pedro como señor de Alcocer. Fue una tardía consecuencia de la vinculación de la comunidad con la dinastía de la fundadora.

En la nueva etapa el monasterio apenas percibe la influencia de los sucesivos señores. En 1323, la viuda del infante don Pedro, la infanta María de Aragón, se ve obligada a conceder su protección al convento frente a los abusos de que su patrimonio era objeto por parte de los vecinos de la villa de Alcocer ${ }^{39}$ Esta modesta gestión, a la que en conciencia venía obligada como titular del señorío, fue el único acto documentado que vincula al monasterio con los señores de la villa en este periodo. De los nuevos señores de la villa no podía esperar la comunidad la actividad y preocupación con que las herederas de la fundadora se habían involucrado en la estabilidad del monasterio y sostenimiento de su patrimonio.

En lo sucesivo, la despreocupación de los nuevos señores de Alcocer, a menudo distantes y en todo caso nunca especialmente comprometidos con la suerte del monasterio, marcó un cambio de tendencia, a tomar en cuenta al explicar la evolución ulterior del patrimonio de la comunidad. A partir de la definitiva desvinculación respecto de la dinastía de la fundadora, la comunidad adquiere, si cabe con más necesidad y convicción de las que desplegó en los últimos años del señorío de la infanta Blanca, un papel protagonista en la gestión autónoma de su patrimonio. En sus relaciones con particulares del entorno,

${ }^{38}$ Castro Garrido, A. 1987. Documentación del monasterio de las Huelgas de Burgos (1307-1321): 332. Burgos: Ediciones JM Garrido Garrido.

39 1323, febrero 12, Zaragoza. La infanta María, viuda del infante Pedro de Castilla, concede su protección al monasterio de Santa Clara de Alcocer. AHN, Clero, libro 4140, fols. 34r-35r.

Hispania Sacra, LXV

132, julio-diciembre 2013, 563-601, ISSN: 0018-215X, doi: 10.3989/hs.2013.030 
no resulta difícil acreditar que el monasterio se reveló como el principal agente en la vida económica de la villa esos años difíciles.

$\mathrm{Al}$ menos desde el comienzo del siglo XIV, Castilla atravesaba por una coyuntura depresiva, cuyas manifestaciones devienen cada vez más perceptibles, y cuyo origen cabe derivarlo de las primeras señales de agotamiento del sistema económico, algo ya percibido desde mediado el siglo XIII. Sobre la posibilidad de atribuir alguna influencia real e inmediata del clima sobre el origen de esta coyuntura depresiva existe en la historiografía alguna controversia. En la península Ibérica, parece posible atribuir algún papel a la sequía como factor que aceleró la crisis en los primeros años del siglo XIV. Hay el conocido testimonio cronístico que plantea un panorama desolador de hambruna, muy probablemente a causa de sucesivas malas cosechas, para el primer año de dicho siglo, ${ }^{40}$ testimonios de grandes sequías en la primera década, ${ }^{41} \mathrm{y}$ algunos otros testimonios que indican la persistencia de veranos secos y muy cálidos en el curso de esa primera década del XIV, siglo que, en términos generales, parece que hoy puede afirmarse que fue «bastante menos lluvioso que el XIII». ${ }^{42}$ Agregando a este panorama climático adverso las consecuencias de una pretendida sobreexplotación agraria y de la extensión de un clima generalizado de inseguridad, que se instala definitivamente en la Corona de Castilla durante la minoría de Alfonso XI ${ }^{43}$ podemos entender que ya el comienzo del siglo XIV fue negativo en términos generales para la economía castellana ${ }^{44}$

Con todo, en torno al cambio de siglo y durante las primeras décadas del siglo XIV, la comunidad de Alcocer desenvuelve su más importante etapa de gestión en lo que a adquisición de rentas de molinos se refiere. ${ }^{45}$ Puede interpretarse que los primeros efectos de la crisis económica afectaron más duramente a los pequeños propietarios rurales, a quienes en 1264 encontrábamos cediendo, en ocasiones a cambio de una remuneración bien modesta, tierras de labor en el término de San

40 «E este año [1301] fue en toda la tierra muy grand fambre; e los omes moríense por las plazas e por las calles de fambre, e fue tan grande la mortandad en la gente, que bien cuidaran que muriera el cuarto de toda la gente de la tierra; e tan grande era la fambre, que comian los omes pan de grama, e nunca en tiempo del mundo vio ombre tan gran fambre ni tan grand mortandad»: 1953. Crónicas de los reyes de Castilla, t. I (BAE LXVI): 119. Madrid, Real Academia de la Historia.

${ }^{41}$ Font Tullot, I. 1988. Historia del clima de España. Cambios climáticos y sus causas: 62. Madrid: Instituto Nacional de Meteorología.

${ }^{42}$ Font Tullot, I. 1988: 63.

${ }^{43}$ Moreta Velayos, S. 1978. Malhechores-feudales: violencia, antagonismos y alianzas de clases en Castilla, siglos XIII-XIV: 89. Madrid: Cátedra.

${ }^{44}$ Sobre la relación entre esta coyuntura depresiva general en la Corona de Castilla y el caso particular de Alcocer, cfr. Martín Prieto, P. 2005 [2]: 291-311.

45 El papel del monasterio clariso de Alcocer como propietario y gestor de intereses en molinos se trata más detenidamente en: Martín Prieto, P. 2006. «Aportación al estudio del molino hidráulico en la Castilla medieval: los molinos del monasterio de Santa Clara de Alcocer». Hispania 224: 833-850. 
Miguel. En un primer momento la capacidad económica del monasterio no resultó demasiado afectada. En las primeras fases de una coyuntura depresiva, y muy especialmente por efecto de la carestía provocada por años de malas cosechas, como al parecer fueron en Castilla los primeros del siglo XIV, hubo alza en los precios del grano, que, sin duda, afectó positivamente, a corto plazo, a los intereses de los rentistas que cobraban en especie, y muy particularmente a la rentabilidad de los molinos. ${ }^{46}$ Por esto, no es aventurado relacionar la importante atención que la comunidad dedica en esos años a la gestión de sus rentas de molinos con la previsible tendencia alcista de los precios del grano en el mismo periodo.

Así, en 1323 la comunidad encarga al molinero de la vecina localidad de Valdeolivas la construcción de una presa y un canal de derivación en el curso fluvial del Riato, a cambio de la cesión de su usufructo por ocho años ${ }^{47} \mathrm{La}$ activa política de gestión de aprovechamientos hidráulicos, llevada a cabo por la comunidad, se prolongará en contratos de arrendamiento, algunos con consecuencias para el patrimonio, suscritos con el mismo molinero en $1328^{48}$ y $1331,{ }^{49}$ y con el paniaguado Domingo Máñez de Beteta, para la construcción de una nueva casa de molinos en $1327 . .^{50}$

Un importante arrendamiento de buena parte de las tierras de labor del monasterio concertado en 1325 con unos particulares de Alcocer puede asimismo ser interpretado como indicio razonable de ese momento de alza en los precios del grano. ${ }^{51}$ En efecto, el hecho de que el arrendamiento fuera concer-

\footnotetext{
${ }^{46}$ Así, atendiendo al alza de precios del cereal, se ha caracterizado el periodo comprendido entre finales del siglo XIII y las primeras décadas del siglo XIV como la edad de oro de la rentabilidad de los molinos: Bois, G. 1976. Crise du féodalisme: 205-211. París: Fondation Nationale de Sciences Politiques. Es impresión confirmada para el caso de la tierra de Burgos, en que la rentabilidad de los molinos parece haberse elevado a partir de mediado el siglo xIII: Ruiz, T. 1981. Sociedad y poder real en Castilla (Burgos en la Baja Edad Media): 71-94. Barcelona: Ariel.

47 1323, septiembre 21, Valdeolivas. El monasterio de Santa Clara de Alcocer contrata con Juan Martín, molinero de Valdeolivas, la construcción de una presa y un caz en el Riato de San Miguel, a cambio de 350 maravedíes y un usufructo de ocho años. AHN, Clero, 567/7.

${ }^{48} 1328$, marzo 8, Valdeolivas. Juan Martín, molinero, vecino de Valdeolivas, recibe del monasterio de Santa Clara de Alcocer, en arrendamiento, por tres años, los molinos y batán del río Guadiela llamados de Mari Cosida. AHN, Clero, 567/11.

49 1331, febrero 9, Valdeolivas. Juan Martín, molinero de Valdeolivas, se compromete a reparar la presa que el convento de Santa Clara de Alcocer tenía en el río del monasterio. AHN, Clero, 567/14.

${ }^{50}$ 1327, agosto 20, Alcocer. Contrato entre Sancha Martínez, abadesa del monasterio de Santa Clara de Alcocer, y Domingo Máñez de Beteta, su paniaguado, para que le construya una casa de molinos con establos para tres bestias, plante la huerta aneja con frutales, y repare el caz, a cambio de disfrutarlo todo en usufructo por cinco años. AHN, Clero, 567/10.

${ }^{51}$ 1325, septiembre 19, Alcocer. El monasterio de Santa Clara de Alcocer cede a Gil Martínez y Pedro de Oñate un conjunto de tierras de cereal en el término de San Miguel, en régimen de arrendamiento por diez años, de 1327 a 1337, a cambio del pago de una renta anual de 30 cahíces de trigo. AHN, Clero, libro 4140, fols. 1r-2r.
}

Hispania Sacra, LXV

132, julio-diciembre 2013, 563-601, ISSN: 0018-215X, doi: 10.3989/hs.2013.030 
tado por la comunidad con estos particulares por diez años, y que en él se estableciera una renta en especie consistente en 30 cahíces anuales de trigo como contraprestación de los arrendatarios por el uso de la tierra, permite suponer un interés de la comunidad por afianzar las bases de percepción de rentas en grano, consolidándolas para el medio plazo, en un momento en que el alza de los precios motivaba su clara revalorización. Nuevamente la importante apreciación de la rentabilidad de los granos en estos primeros años de la crisis aparece como principio director de la política patrimonial y de gestión autónoma llevada a cabo por el monasterio, tal y como se observó para el caso de las rentas de los molinos.

La integración de nuevos recursos se produce, en este periodo, principalmente, por donaciones. La más importante fue la de la infanta Blanca en su testamento. Hubo otras donaciones, de particulares vinculados al convento. En 1327, Diego Ruiz, antiguo escribano de la infanta Blanca, compró unas casas en Cifuentes. ${ }^{52} \mathrm{El}$ hecho de que el documento de la compraventa se haya conservado en el archivo conventual hace suponer que, con posterioridad, estas casas fueron donadas al monasterio. Muy parecido es el caso de la compra, por parte del clérigo Martín Pérez, de unas casas en Hita en $1329 .{ }^{33}$ Concluida la operación, el comprador cedió la propiedad a su sobrina Estefanía, cuyo ingreso en el convento explicaría que este documento se conservara en el archivo del monasterio.

Un último caso de donación durante esta época, documentado de forma mucho más clara y directa, es el de un vecino de Cifuentes, que dona una casa de molinos en 1335, con la condición de retener el usufructo mientras durara su vida y la de su hijo. ${ }^{54}$ No es inverosímil que por parte de esa familia mediara voluntad de eludir impuestos, cediendo la propiedad del bien afectado, pero reteniendo los beneficios de su uso en forma vitalicia. En todo caso la parada de molinos pasó a ser patrimonio del monasterio.

Otro ejemplo de adquisición: en 1326 la abadesa de Alcocer compró de una particular una tierra en el término de la cercana población de Millana. ${ }^{55} \mathrm{Tal}$ vez quepa ver en este documento una corriente típica de estos años de crisis: los

52 1327, junio 17, Cifuentes. Juan Pérez de Luca y su esposa Gila venden a Diego Ruiz, escribano de la infanta Blanca, varias casas de la villa de Cifuentes. AHN, Clero, 567/9.

53 1329, marzo 23, Hita. Martín Pérez vende al clérigo Juan Gómez unas casas en Hita, y luego este último se las cede a su criada Estefanía. AHN, Clero, 567/12.

54 1335, septiembre 12, Cifuentes. Gil Pérez de Atienza, su mujer Constanza y su hijo Francisco López, vecinos de Cifuentes, donan al monasterio de Santa Clara de Alcocer una casa de molinos en la cuesta cerca de Cifuentes, reservándose su usufructo vitalicio. AHN, Clero, 567/16.

55 1326, octubre 5, Alcocer. María Sánchez vende a Teresa Fernández, abadesa del monasterio de Santa Clara de Alcocer, una tierra en la Fuente Vela, término de Millana. AMA, libro A1, fols. $183 \mathrm{r}-184 \mathrm{r}$. 
pequeños propietarios agrarios se desprendían de sus tierras en beneficio de los poderosos, siendo en estos años el monasterio sin duda uno de los principales agentes económicos de Alcocer.

\section{LOS EFECTOS DE LA CRISIS EN EL PATRIMONIO (1337-1371)}

Un documento conservado en el archivo aporta noticias muy interesantes para la descripción del patrimonio en 1337. Se trata del inventario general de los bienes del monasterio elaborado por la comunidad por encargo del ministro franciscano de la provincia de Castilla, siguiendo instrucciones del Papado. ${ }^{56}$ La confección del inventario no resultó del todo satisfactoria para el provincial de Castilla, a juzgar por las expresiones que fray Simón añadió al ratificar y sellar los dos ejemplares que le fueron presentados. En la ratificación, el ministro provincial instó a la comunidad a que reelaborara el inventario de manera más exhaustiva y rigurosa, de forma que sus capítulos resultasen «mas conplidos». Por desgracia, no hemos obtenido noticia de ninguna providencia ulterior tomada por la comunidad para completarlo. Hay que conformarnos, por el momento, con su primera redacción, única conservada en el que fue archivo del monasterio, y posiblemente única que finalmente se acometió.

El inventario contiene una descripción, en ocasiones demasiado genérica y poco detallada, de los distintos capítulos que en esa fecha integraban el patrimonio, siendo un instrumento de la máxima utilidad e interés para su caracterización, una suerte de «instantánea», bien que aproximada e inexacta, con adición de detalles sobre los que ningún otro documento conservado da noticias. Pues bien, la impresión general que transmite es de decadencia. Muchos recursos con los que la comunidad contaba desde los primeros tiempos de su existencia se hallaban en 1337 abandonados o infrautilizados. Otros habían mermado por alguna agresión externa.

La imagen de decadencia afecta en primer lugar a las tierras de labor. De las de cereal, que rodeaban el monasterio en el término de San Miguel, en el inventario se dice que las cultivan los servidores de la comunidad, y que «siembran, et non cogen». De las situadas en el mismo término propio de Alcocer, unas están arrendadas, pero lo que rentan «tomaron se nos los de Alcoçer», y lo restante «a fincado erio, et es perdido, que non se labra». Diez aranzadas de viñas están igualmente «erias et perdidas». Por falta de mano de obra, por malas cosechas, motivadas por el clima, o por la morosidad de los arrendatarios, la producción agrícola de las numerosas tierras del monasterio atravesaba un momento crítico.

56 1337, agosto 12, Guadalajara. Inventario general de los bienes y rentas del monasterio de Santa Clara de Alcocer, elaborado por mandato del Papa. AHN, Clero, 567/17 y 567/18.

Hispania Sacra, LXV

132, julio-diciembre 2013, 563-601, ISSN: 0018-215X, doi: 10.3989/hs.2013.030 
La situación de los molinos tampoco es buena. Casi todos eran gestionados indirectamente a través de arrendamientos que aportaban rentas en especie, pero «los de Donate estavan erios, et dieron los por veynte annos, por que los refiziesen». Se cita la renta de cereal que el monasterio debía percibir cada año en Palazuelos, para aclarar que está perdida, por causa de «las guerras». Alusión al clima de desorden e inseguridad que atravesó Castilla en estos años. Rebeliones, encabezadas por nobles levantiscos, como Juan Núñez de Lara, Juan Alfonso de Haro, y don Juan Manuel, asolaron con frecuencia la tierra, impidiendo la actividad económica. ${ }^{57} \mathrm{La}$ misma razón se aduce para explicar la inconstancia e inseguridad de la renta burgalesa dejada por la infanta Blanca en su testamento, y la ausencia de todo ingreso procedente de la renta del portazgo de Cifuentes, «con estas guerras, dos annos a que non avemos nada».

El resultado fue el endeudamiento de la comunidad. En el citado inventario se enumeran distintas deudas contraídas con ciertas dignidades del convento, como la abadesa, el confesor y el mayordomo, pero también con particulares de tan humilde extracción como los «collaços et las collaças», esto es, los servidores dependientes del monasterio.

Pueden destacarse dos puntos de interés a propósito de estas deudas. Primero: la comunidad evitó al parecer endeudarse con personas ajenas al convento. Segundo: las deudas son contraídas no para proceder a compras u operaciones ambiciosas de ampliación del patrimonio, sino para cubrir necesidades tan básicas como comprar pan, sal para el ganado, vino, y carne. Es un indicador de las dificultades de aquel momento y confirman el estado «de subsistencia» en que se encontraba el patrimonio, sin la menor posibilidad de emprender nuevas y ambiciosas iniciativas para su incremento.

Como hemos observado, ${ }^{58}$ las raíces profundas de las manifestaciones de estancamiento y decadencia en el patrimonio monástico, que este inventario revela, se hunden en un fenómeno mucho más amplio que las incursiones periódicas de notables revoltosos en la tierra de Huete. El origen de la situación se cifra, a qué dudarlo, en el contexto económico general, de signo claramente depresivo, que comenzó hacia mediados del siglo XIII y se intensificó en la primera mitad del siglo xIv. Los mencionados testimonios que permiten dibujar una imagen de los efectos de la crisis desde los primeros años del siglo XIV son síntomas de general pobreza, despoblación, hambre y carestía. A ellos se unen otros relacionados con el clima extendido de violencia e inseguridad en buena parte de Castilla. Así, los procuradores de las villas y ciudades llevan

57 Pretel Marín, A. y Rodríguez Llopis, M. 1998. El señorío de Villena en el siglo XIV: 79-81. Albacete: Diputación Provincial.

${ }^{58}$ Martín Prieto, P. 2005 [2]: 298-304. 
a las Cortes sus quejas sobre la situación de despoblación y pobreza de la tierra..$^{59}$

La inseguridad, que tanto dificultaba el desempeño de la actividad económica, al parecer, aumentó de forma muy sensible durante la turbulenta minoría de Alfonso XI. ${ }^{60}$ La crónica de este monarca refiere cómo en 1325, año en que, acabada su menor edad, asumió personalmente su reinado, «falló al regno muy despoblado et muchos logares yermos», en buena medida como resultado de la violencia que había asolado la tierra durante la problemática etapa que entonces tocaba a su fin, violencia por causa de la cual «las villas del rey et todos los otros logares de su regno rescebían muy grand daño et eran destroidos». ${ }^{61}$

Este panorama desolador afectó directamente a las rentas señoriales y a las rentas de los dominios monásticos, como se ha demostrado suficientemente, por ejemplo, para el caso de los monasterios benedictinos de la provincia de Toledo, de los que cabe apuntar una «situación deficitaria» para 1338, fecha muy cercana a la del inventario de Alcocer. ${ }^{62}$ En particular, una de las principales manifestaciones de esta coyuntura depresiva, cual es el desaforado aumento de los precios del grano, se puede documentar con seguridad en esos años. ${ }^{63}$

Todo en el inventario de 1337 confirma la entrada del patrimonio del monasterio en una etapa de estancamiento, que durará hasta que el cambio dinástico le aporte nuevas bases. En este periodo considerablemente prolongado, pocas son las variaciones que experimenta el patrimonio. Quizás deba creerse que la extraordinaria penuria documental de este periodo, en cuyo centro se encuentra la Peste Negra ${ }^{64}$ constituye en sí mismo un indicio bien elocuente del agravamiento de la crisis.

${ }^{59}$ Cortes de los antiguos reinos de León y Castilla. t. I. 1881: 187. Madrid: Real Academia de la Historia: «por que la mi tierra era muy yerma e muy pobre» (1307).

${ }^{60}$ En las cortes de Valladolid de 1312 se alude a militares menores («escuderos» y «peones lançeros») que saqueaban villas y aldeas con amenazas (Cortes. I. 1881: 218); en las celebradas en Carrión en 1317 se mencionan los muchos «robos», «fuerças» y «tomas» que desde la muerte de Fernando IV menudearon en Castilla (Cortes. I. 1881: 303-304); en las de Valladolid de 1322 se repite la queja por las «assonadas [...] dannossas», a las que se culpa del hecho de «quela mayor partida delos rregnos es astragada» (Cortes. I. 1881: 351).

${ }^{61}$ Crónicas I. 1953: 197.

${ }^{62}$ Sobre las manifestaciones de la crisis en estos cenobios, cfr. Pérez Celada, J. A. 1998. «Algunas consideraciones sobre la conducta de los monjes cluniacenses ibéricos en la Baja Edad Media», en VIII Semana de Estudios Medievales (Nájera): 294-295. Logroño: Instituto de Estudios Riojanos.

${ }^{63}$ Así, sabemos por ejemplo que en 1332 en el monasterio de San Juan de Burgos hubieron de empeñar algunos bienes inmuebles por causa de una mala cosecha, con el objeto de comprar pan para el consumo de la comunidad, «por ser el pan en Castilla muy caro e non avian pan en el dicho monasterio»: cfr. Moreta Velayos, S. 1974. Rentas monásticas en Castilla: problemas de método: 141. Salamanca: Universidad.

${ }^{64} \mathrm{Si}$ bien no subsiste constancia documental alguna, ni aun indicio verosímil, de que Alcocer o la comarca fueran afectadas por dicha pandemia mediosecular.

Hispania Sacra, LXV

132, julio-diciembre 2013, 563-601, ISSN: 0018-215X, doi: 10.3989/hs.2013.030 
La obscuridad envuelve los años centrales del siglo xIv. En la serie de la documentación del archivo de las clarisas de Alcocer esas décadas centrales del siglo XIV son, con mucho, el periodo peor documentado, un verdadero punto de inflexión que muy probablemente denota una situación de impasse en la evolución del patrimonio, motivada por la dura situación que esos años debió de atravesar la comunidad..$^{65}$ En un año muy malo, 1345 , en que se produjo fuerte mortandad de ganados y cosechas catastróficas como resultado de un invierno especialmente crudo, ${ }^{66}$ Alfonso XI concedió al monasterio de Alcocer doce servidores excusados de todo tributo, ${ }^{67}$ importante merced, confirmada por Enrique II en $1371,{ }^{68} \mathrm{e}$ indicio de la preocupación de la monarquía por promover o facilitar una reactivación económica de este monasterio.

Por otra parte, cabe considerar que esta merced fuera mera confirmación de usos ya acuñados, como sugiere la aparición de paniaguados y excusados en la documentación con anterioridad a esa concesión regia. ${ }^{69}$

Las únicas operaciones realizadas por la comunidad en este obscuro periodo son, en 1339, un contrato de arrendamiento de los molinos de Donato, con la obligación de añadirles nuevos equipamientos: ${ }^{70} \mathrm{y}$ en 1356 una permuta menor de algunas tierras de cereal con un vecino de Alcocer. ${ }^{71}$ Ambas suponen modificaciones en el patrimonio, pero de escasa importancia, de forma que en modo alguno impiden caracterizar esta época como de declive.

En conclusión, este periodo, que se ciñe más o menos a la mitad central del siglo XIV , absorbió la mayor parte de los efectos de la crisis económica general tal y como afectó a Alcocer. En cuanto a la evolución del patrimonio del

${ }^{65}$ Afecta al mismo periodo la deliberada supresión posterior — o mera falta de confirmación — de los documentos emanados de la cancillería del rey Pedro, pero este factor sólo ayudaría a explicar la merma de documentación de origen regio.

${ }^{66}$ Cortes de Burgos de 1345: «en este anno en questamos fue muy grant mortandat en los ganados, e otrosi la simiença muy tardia, por el muy fuerte tenporal que ha fecho de muy grandes nieves e de grandes yelos»: Cortes I. 1881: 484 .

67 1345, noviembre 18, Madrid. Alfonso XI concede al monasterio de Santa Clara de Alcocer 12 excusados libres de todo pecho, de 600 maravedíes cada uno; excusa a los hombres del convento del pago de portazgo sobre todo aquello que llevaren al convento; y otorga su amparo y protección a la comunidad. AHN, Clero, 568/1.

68 1371, marzo 26, Valladolid. Enrique II otorga al monasterio de Santa Clara de Alcocer doce hombres excusados de todo pecho. AHN, Clero, 568/6; también en: Clero, libro 4140, fols. 134r-139v.

${ }^{69}$ Así en 1323 (AHN, Clero, libro 4140, fols. 34r-35r) y en 1327 (AHN, Clero, 567/10).

70 1339, diciembre 5, Alcocer. El monasterio de Santa Clara de Alcocer da en arriendo a Juan Martín, su hijo Domingo Fernández y a Pedro Martínez, una casa de molinos harineros (el molino de Donato) sobre el río Guadiela, por seis años (hasta el 20 de julio de 1346), a cambio de que dejen al convento dos ruedas de molinos cerca del mismo, tal como se comprometió. AHN, Clero, 567/19.

71 1356, febrero 24, Alcocer. Ferrán Sánchez, vecino de Alcocer, cambia a Mari Sánchez, abadesa del convento de Santa Clara de Alcocer, dos tierras de cereal, por otras. AHN, Clero, 568/2. 
convento, puede afirmarse que resultó punto menos que estéril. La siguiente etapa dará lugar a un intento de reactivar la economía monástica por medio de nuevas incorporaciones patrimoniales, gracias a la iniciativa de la monarquía.

\section{NUEVAS BASES ECONÓMICAS CON El CAMBIO DINÁSTICO (1371-1401)}

La implantación de la nueva dinastía Trastámara en el trono supone el arranque de una nueva etapa no sólo para la historia de la Corona de Castilla, sino también para el patrimonio del monasterio de Alcocer. Después de una época de decadencia y penuria, mejorará su situación. Afianzada ya su independencia respecto de los señores de la villa, en poco afectó a la comunidad el relevo en la titularidad del señorío. Será la corona la que le dé el necesario empuje para salir de su estancamiento e iniciar una nueva etapa asentada en nuevas bases patrimoniales.

En estos primeros años de los Trastámara, asistimos a una suerte de renovación de la protección regia sobre el monasterio, en un momento en que parece reproducirse, en nuevas circunstancias, el esquema que, en torno a 1260, dio origen a la fundación del convento. En su origen está la reactivación de la protección regia, cuya manifestación más visible y de más honda repercusión es sin duda el traslado de la comunidad a un nuevo edificio erigido en el interior de la villa de Alcocer.

El monasterio era de fundación regia. Para explicar las razones de su renovación, acaso no baste esa consideración y sea de interés mencionar en este punto los lazos que ligaban a la nueva familia real Trastámara con el señorío y con el monasterio.

Sabemos que el rey Enrique II se sentía vinculado estrecha y comprensiblemente con el linaje de su madre (los Guzmán), que había compartido con Alfonso X el protagonismo en la fundación y en la primera formación de su patrimonio monástico. Su esposa, la reina Juana Manuel, era descendiente del linaje manuelino, vinculado de antiguo con la suerte de la comarca de la Hoya del Infantado, cercana a Alcocer, y estaba relacionado con el convento. ${ }^{72}$ En consecuencia, no parece descabellado postular un interés directo y familiar de la primera pareja real de la nueva dinastía en la reactivación de la protección de la corona esos años y que envuelve la operación de traslado, siendo casi un eco o remedo, en un momento de refundación, del esquema original que había permitido la fundación del monasterio.

${ }^{72}$ La decisiva intervención del primer monarca Trastámara y de su familia en el proceso se describe y contextualiza en: Martín Prieto, P. 2007. «Sobre la promoción regia de la orden franciscana en la Corona de Castilla durante el primer reinado Trastámara». Hispania Sacra 119: 51-83.

Hispania Sacra, LXV

132, julio-diciembre 2013, 563-601, ISSN: 0018-215X, doi: 10.3989/hs.2013.030 
Tres son los importantes puntos en los que se apoya esta nueva orientación de recuperación y reactivación de las bases patrimoniales del convento, contando los tres con la intervención de la monarquía. Primero, en 1371 Enrique II otorga nuevamente al monasterio, sin mencionar la vieja merced otorgada por Alfonso XI en el mismo sentido, que tenga doce servidores excusados de todo tributo, a excepción de la moneda forera. ${ }^{73}$ La reiterada concesión de este privilegio da idea de la importancia económica de la exención tributaria que llevaba aparejada. Su nueva concesión pone en pie uno de los pilares básicos sobre los que la comunidad renovará sus bases económicas.

Después de una época presidida por el desorden general y los conflictos con los vecinos de la villa, la comunidad se convenció de que su ubicación excéntrica y rural, en el término despoblado de una antigua aldea, ya no era sostenible. Buscó pues, y obtuvo, la ocasión de trasladarse a un nuevo emplazamiento dentro de los muros de la villa. Los motivos para solicitarlo eran lo remoto, despoblado e inseguro del primer emplazamiento del monasterio, y los daños irrecuperables que había recibido en la reciente época de desórdenes y guerra. ${ }^{74}$

Por su interés, conviene seguir paso por paso el proceso para llevarlo a cabo. La abadesa expuso la reivindicación de la comunidad en 1372 al legado pontificio en España, el cardenal Guido de Boulogne, entonces de visita en la comarca alcarreña. Concedida por el legado la autorización para iniciarlo,${ }^{75}$ la comunidad hizo llegar su petición, a través de una propuesta presentada por fray Juan González de Huete, al capítulo general de la orden franciscana, celebrado en 1373 en Toulouse. En él se acordó pedir al monarca castellano su autorización para consumar el traslado, considerando que el monasterio de Alcocer era de

${ }^{73}$ AHN, Clero, 568/6. Vide supra, nota 67.

${ }^{74}$ Dichos motivos, tal como fueron expuestos por la abadesa Estefanía al legado pontificio Guido, figuran en el permiso para el traslado concedido por este último: «locus in quo dictum monasterium olim constructum extitit, est solitarius, et ab omni fortalicio ualde distans et remotus: quodque propter distanciam et solitudinem huiusmodi, moniales ibi secure uiuere non possunt; dictumque monasterium per depredatores et guerras que in regno Castelle hactenus inquerunt adeo dampnificatum, destructum et dissipatum existit, quod de restauracione ipsius monasterii non speratur»: 1372, diciembre 15, Guadalajara. Guido de Boulogne, legado apostólico, concede a la diócesis de Cuenca el permiso para el traslado del monasterio de Santa Clara de Alcocer a un nuevo emplazamiento en el interior de la villa. AHN, Clero, 568/3. Un eco de los mismos se percibe en la concesión del permiso para el traslado otorgado por Enrique II: «por razon que el monesterio de las duennas de Santa Clara de Sant Miguell çerca de Alcoçer esta en un monte que es en logar yermo, et non esta en logar seguro nin honesto para duennas, por quanto cada que acaesçen algunos bolliçios en la tierra se an de yr las dichas duennas del dicho monesterio a unas partes et a otras, et finca yermo et despoblado el dicho monesterio»: 1373, julio 7, Burgos. Enrique II, solicitado por una comisión del capítulo general de la orden franciscana, concede licencia al convento de Santa Clara de Alcocer para mudarse del monasterio fundado por Mayor Guillén a otro nuevo dentro de la villa. AHN, Clero, 568/4.

${ }^{75}$ AHN, Clero, 568/3. Vide supra, nota 73. 
fundación regia ${ }^{76}$ Cabe suponer que se inició inmediatamente después de la autorización regia en julio de 1373, ya que el documento de Enrique II otorga su permiso para el traslado «al dicho monesterio que agora nueva mente es fecho en la dicha villa de Alcoçer», ${ }^{77}$ expresión que no deja lugar a dudas sobre el hecho cierto de que a tal fecha el nuevo recinto ya se hallaba en condiciones de albergar a la comunidad.

Ignoramos tanto el momento en que se emprendió la construcción de la nueva sede dentro del núcleo amurallado, como la procedencia del importante volumen de recursos que esa construcción debió comportar. La tradición de la comunidad, de la que bebe el historiador franciscano Ortega ${ }^{78}$ indica que la construcción fue sufragada por el rey y por su contador mayor, Sancho Fernández de Cifuentes, al que pronto encontraremos asociado a la concesión de otra donación importante para el convento.

Sin embargo, parece posible atribuir un papel destacado a la iniciativa y al impulso de la reina castellana Juana Manuel como origen y sostén preeminente que hizo posible emprender y consumar la importante operación. Al interés que, como descendiente del linaje manuelino, cabía esperar de ella para apoyar al monasterio, hemos de añadir la índole de su piedad religiosa, orientada muy especialmente a favorecer a los conventos clarisos, que durante su vida gozaron de la predilección de su generosidad. Fue una suerte de caso particular dentro de la política general de fomento de las órdenes mendicantes del primer reinado Trastámara, ${ }^{79} \mathrm{y}$ parece posible establecerla partiendo de algunas fuentes historiográficas, según las cuales la reina «dejó jamás en vida y muerte el hábito de santa Clara». ${ }^{80}$

Pues bien, también es posible acreditar, en circunstancias muy similares a las que rodearon el traslado del convento de Alcocer, y sobre las mismas fechas, la participación directa y activa de la reina Juana Manuel en la operación de traslado que afectó a las clarisas de Palencia.$^{81}$ El papel de la reina Juana Manuel en

${ }^{76}$ Wadding, L. 1932. Annales Minorum seu Trium Ordinum a Sancto Francisco Institutorum, t. IX (1377-1417): 73. Quaracchi: Collegio San Bonaventura.

${ }^{77}$ AHN, Clero, 568/4.

${ }^{78}$ Ortega, M. 1740. Chronica de la Santa Provincia de Cartagena, t. I: 41-42. Murcia: Francisco López Mesnier.

${ }^{79}$ De esta política favorable a las órdenes mendicantes de Enrique II es expresiva muestra la merced concedida en las Cortes de Toro el 6 de noviembre de 1371, cuando el rey declaró exentas a las órdenes mendicantes de las tasas de cancillería, con tintes de exclusividad: «e que otros ningunos non sean escusados de pagar chançelleria, saluo los que dichos son»: cfr. Cortes II: 228.

${ }^{80}$ GARIBAY, E. 1628. Compendio historial de las chronica y universal historia de todos los reynos de España, t. II: 354, col. A. Barcelona: Sebastián de Cormellas.

${ }^{81}$ Castro, M. 1982. El Real Monasterio de Santa Clara de Palencia y los Enríquez, Almirantes de Castilla: 21-28. Palencia: Diputación Provincial.

Hispania Sacra, LXV

132, julio-diciembre 2013, 563-601, ISSN: 0018-215X, doi: 10.3989/hs.2013.030 
este traslado dentro de los muros de la población se concretó en la compra de las casas donde se asentaría de nuevo la comunidad, y en la defensa de la operación frente a la oposición inicial del obispo de la diócesis.

En el caso palentino fue asimismo la reina quien se ocupó de solicitar y obtener de Roma la licencia apostólica necesaria para la construcción y consagración del nuevo monasterio situado intra muros. Esta operación fue también autorizada, como en el caso de Alcocer, por el legado Guido de Boulogne, aduciendo motivos muy similares, llegando a utilizar probablemente un mismo formulario para la redacción de las dos licencias, las concedidas por el mismo legado a las comunidades de Alcocer y Palencia para sus traslados respectivos ${ }^{82}$ Este hecho habla en favor de una política consciente impulsada por el legado pontificio contando con la anuencia y el compromiso activos de la reina Juana Manuel, para promover que se situaran dentro de las murallas los conventos hasta entonces en lugares desamparados y remotos.

El traslado de las clarisas de Alcocer es un ejemplo. Además debe tenerse presente el interés familiar que, para apoyar esta merced, movía a Enrique II, declarado sin ambages en el privilegio de autorización. En él recuerda expresamente que la fundadora del monasterio, doña Mayor Guillén, había pertenecido al linaje de los Guzmán, el mismo de la madre del Rey. ${ }^{83}$

Intervino el contador Sancho Fernández, de quien sabemos que esos años se involucró de manera decisiva y significativa, al menos en otra importante operación para dotar al monasterio de nuevas bases económicas. Se concedió a la comunidad una participación de hasta 2200 maravedíes anuales en la renta realenga de almojarifazgo de las ollerías de Triana, en la ciudad de Sevilla, renta de la que, al parecer, con anterioridad había sido beneficiario el mismo Sancho Fernández y que, de común acuerdo con sus señores, Enrique II y Juana Manuel, vinculó en 1377 al patrimonio del monasterio.

La donación figura en un documento muy importante, lleno de noticias significativas. ${ }^{84}$ Lo encabeza el rey Enrique II, pero lo suscribe su esposa la reina Juana Manuel. En la exposición de motivos, el rey expresa su voluntad de rea-

${ }^{82}$ Cfr. el documento autorizando el traslado de las Clarisas de Palencia, del Archivo del Monasterio de Santa Clara de Palencia, caja $1^{\mathrm{a}}$, $\mathrm{n}^{\mathrm{o}}$ 3, en Castro, M. 1982: 21-22.

83 «Mayor Guillem, duenna que fuera del linaje de los reyes onde nos venimos»: AHN, Clero, 568/4.

${ }^{84}$ 1377, diciembre 22, Palencia. Enrique II funda siete capellanías perpetuas en Alcocer, dotadas en las rentas del almojarifazgo de ollerías de Sevilla, tres en la iglesia parroquial, dos en el monasterio de Santa Clara y las otras dos en el convento de San Francisco. AHN, Clero, libro 4138, fols. 11v-16v. La transcripción de este documento, junto con un estudio del conflicto con los olleros sevillanos que acarreó en el siglo xv, se pueden consultar en: Martín Prieto, P. 2008. «Los olleros de Sevilla contra los capellanes y conventos de Alcocer: un pleito del siglo XV». Historia. Instituciones. Documentos 35: 291-307. 
signar la renta realenga de las ollerías de Triana, cedida a Sancho Fernández, su contador mayor, para destinarla a las fundaciones piadosas que decidiera la reina Juana. Informa que ésta ha decidido destinar la renta a la fundación y dotación de siete capellanías perpetuas en la villa de Alcocer, tres en la iglesia parroquial de Santa María, dos en el monasterio franciscano de San Miguel, y otras dos en el monasterio de Santa Clara. Sin embargo, en las condiciones se dice: si los frailes franciscanos del monasterio de San Miguel no quisieran desempeñar las dos capellanías que les corresponden, conservarían la renta anual de 2200 maravedíes como limosna; en el caso del monasterio de Santa Clara, se asigna la renta correspondiente a las dos capellanías restantes directamente a los usos que quisiera darle la comunidad («para reparamiento del dicho monesterio [...], y lo que sobrare [...] en limosna para aiuda de su mantenimiento»), asumiendo de antemano que nunca iban a dotarlas y desempeñarlas de manera efectiva.

La intervención de Sancho Fernández en la transferencia de estas rentas a la iglesia parroquial y a los dos conventos de Alcocer queda suficientemente acreditada, pues se vincula la elección de los candidatos para el desempeño de las capellanías a su decisión personal, y faltando aquél, a la de sus herederos, reconociéndole, bien que de modo indirecto, la preeminencia que correspondía a un fundador o patrono.

Formalmente, son los reyes quienes fundan las capellanías y dotan las rentas, pero sabemos que lo hacían en colaboración con Sancho Fernández, confirmante del documento de concesión, y titular hasta entonces de la renta de las ollerías de Triana.

La merced está estrechamente vinculada con la tierra del Infantado: los capellanes llamados a desempeñar las capellanías deberían proceder de Alcocer, y en su defecto, de Salmerón, Valdeolivas, o de «otro qualquier logar de los de entre Tajo y Guadiela, quales el dicho Sancho Fernandez viere en su vida». Esta condición nos indica que Sancho Fernández procedía muy probablemente de esa tierra, si no del mismo Alcocer ${ }^{85}$ y que promovió activamente la reasignación de las rentas de Triana que administraba, situándolas en lugares a los que estaba estrechamente vinculado. El papel protagonista que el documento de concesión otorga a la reina Juana Manuel, a quien correspondía asignar esas rentas, puede tomarse como un indicio en favor de la suposición de que muy probablemente el mismo Sancho Fernández procedía de su casa.

Para el convento de Santa Clara la concesión incondicional de esta renta anual de hasta 2200 maravedíes supuso un definitivo espaldarazo a su nueva ubicación dentro de la villa. En consecuencia, puede entenderse que en el inicio de una nueva etapa la nueva dinastía Trastámara aseguró unas bases económicas

${ }^{85}$ Si bien la tradición oral de la comunidad lo quiere natural de Cifuentes. 
suficientes y estables, con la dotación de nuevos y generosos recursos para su reactivación como institución de la vida religiosa y la reorganización de su patrimonio. Este apoyo fue confirmado por sus inmediatos herederos ${ }^{86}$ antes de dar paso a una etapa de estabilización, en la protección de la corona y en la evolución del patrimonio monástico, que puede vincularse en sentido amplio con el siglo Xv.

ESTABILIZACIÓN DURANTE LA MAYOR PARTE DEL SIGLO XV (1402-1483)

Por desgracia, se ha perdido la mayor parte de la documentación en papel generada por este convento a lo largo del siglo xv. Esta documentación cabe suponer, tratándose de este siglo, que habrá sido copiosa, pero apenas subsisten magros vestigios en los fondos procedentes del archivo de la comunidad que atesora todavía el Archivo Histórico Nacional. Esto no permite ahondar con detalle en la vida económica de la comunidad en el periodo.

La atenta consideración de una serie de hitos consignados en los documentos permite obtener una imagen de una recuperación, modesta quizás pero sostenida, del patrimonio de las clarisas, desde de su traslado al nuevo monasterio en el interior de la villa. Esta estabilización del patrimonio, en lo fundamental, es fruto de la gestión autónoma de la comunidad. La recepción de mercedes y donaciones se ha detenido, pues en esta etapa sólo se registran algunas incorporaciones patrimoniales, resultado de la recepción ocasional de legados testamentarios, sin que puedan documentarse mercedes o donaciones de la trascendencia o cuantía de las que acompañaron el traslado al monasterio intra muros. Puede afirmarse que en el siglo XV la intervención de los señores de Alcocer en la evolución del patrimonio del monasterio se torna punto menos que irrelevante. El principal motor de la evolución patrimonial es la actividad económica de la propia comunidad, especialmente en una dirección ahora inaugurada, de especial importancia en esta etapa y en los primeros tiempos de la Edad Moderna: se trata de la concertación de arrendamientos a muy largo plazo sobre importantes capítulos de bienes del patrimonio inmueble del monasterio: censos enfitéuticos.

Durante la mayor parte del periodo, la intervención de la monarquía se limita a confirmar, en cada comienzo de reinado, lo aprobado sobre bienes, usos y mercedes anteriores ya disfrutados. ${ }^{87}$

\footnotetext{
${ }^{86}$ Así en las cortes de Burgos de 1379 Juan I procedió a confirmar el privilegio de los doce excusados (AHN, Clero, 568/6) y a otorgar una confirmación general de privilegios, usos y mercedes al monasterio clariso de Alcocer (AHN, Clero, 568/5 y 568/7); esta última confirmación general fue asimismo suscrita por Enrique III en 1401 (AHN, Clero, 568/7).

${ }^{87}$ Juan II concede el 4 de abril de 1408 una confirmación general (AHN, Clero, 568/17, 568/19, y 569/7) que a su vez será confirmada por Enrique IV el 20 de febrero de 1459 (AHN, Clero, 568/17).
} 
Cabe recordar que las órdenes mendicantes disfrutaron de plena exención de derechos de cancillería desde las cortes de Toro de 1371 y, en consecuencia, debe entenderse que las clarisas de Alcocer no tuvieron que realizar desembolso alguno, ni grande ni pequeño, por la renovación y confirmación de sus privilegios a partir de la fecha mencionada, en un periodo que comprende las cruciales confirmaciones de Juan I y Enrique III, ${ }^{88}$ destinadas a consolidar las nuevas bases materiales del patrimonio constituidas durante el reinado de Enrique II, y más tarde las confirmaciones generales, otorgadas por Juan II y Enrique IV hacia el comienzo de sus reinados respectivos.

En noviembre de 1417 Teresa Díaz, viuda de Sancho Fernández de Cifuentes, que favoreció con largueza al monasterio, y tuvo destacada intervención en el traslado, y en la asignación de la importante renta de las ollerías de Sevilla, incluyó en su testamento alguna manda para la obra de la iglesia parroquial de Alcocer, donde pidió ser enterrada, en la misma sepultura de su padre. Esta señora dejó fuera el monasterio clariso de Alcocer. Nada sorprende, pues su marido ya había favorecido en vida a las clarisas de manera suficiente y generosa. Pero ¿cómo explicar que una copia del testamento se haya conservado en el archivo del convento? Eso exige analizar la ejecución del testamento en cuestión, que se produjo un año y medio más tarde, en abril de 1419.

En esa fecha, los testamentarios de Teresa Díaz, para cumplir las mandas, procedieron a vender en pública almoneda dos tercios de una viña situada en el paraje conocido como la Senda del Galletero, en Alcocer. La subasta ofrece algún interés: en las dos primeras rondas del proceso la oferta mejor fue la de un capellán, Juan Díaz, por una suma de 2000 maravedíes. Sin embargo, en la tercera y definitiva ronda, esa oferta fue sobrepujada por un tal Sancho Fernández de Peromingo, vecino de Alcocer, quien pagó por los dos tercios de la viña la cantidad de 2500 maravedíes. Pues bien, nada más haber adquirido el bien, este vecino de Alcocer procedió a renunciar su propiedad y a traspasarla a Pedro Martínez, quien actuaba como procurador y representante legal de Constanza de Villena, madre de quien a la sazón era señora de Alcocer, María de Albornoz, y ella misma involucrada en la gestión de los asuntos del señorío ${ }^{89}$ Todo parece indicar que hubo una maniobra de distracción realizada por Constanza de Villena para apoderarse de la viña, de manera indirecta y encubierta, a través de interpuesta persona, maniobra quizás motivada por el deseo de vencer cierta reserva que a los testamentarios habría podido inspirar

${ }^{88}$ AHN, Clero, 568/5, 568/6 y 568/7.

${ }^{89}$ Sobre la titularidad del señorío de Alcocer por los Albornoz, véase: Martín Prieto, P. 2011. «De los Albornoz a los Mendoza: la transmisión del estado señorial del Infantado de Huete en la Baja Edad Media». En la España medieval 34: 229-247.

Hispania Sacra, LXV

132, julio-diciembre 2013, 563-601, ISSN: 0018-215X, doi: 10.3989/hs.2013.030 
la posibilidad de haber contribuido a incrementar las posesiones de la familia señorial de Alcocer. ${ }^{90}$

Como fuere, lo cierto es que a partir de abril de 1419 esa viña pasa a ser propiedad de Constanza de Villena. Dos hechos nos sugieren que Constanza a su vez cedió la propiedad a las clarisas de Alcocer. En primer lugar, que el documento en el que se recoge todo el proceso y una copia del testamento de Teresa Díaz se hayan conservado en el archivo de la comunidad. En segundo lugar, esta viña había sido de Teresa Díaz y era lindera con otra de las monjas. Todo ello permite suponer que, en fecha incierta, Constanza de Villena o su heredera María de Albornoz procedieron a donar estas dos terceras partes de la viña de la Senda del Galletero al monasterio, interesado en redondear sus propiedades en la zona uniéndolas a la viña que poseía en el mismo lugar. De esta forma podría conjeturarse que el fin de toda la operación habría sido una intervención de Constanza para incrementar el patrimonio de las clarisas.

Su testamento es otro testimonio más directo de la intervención de Constanza de Villena en la incorporación de bienes al patrimonio monástico de las clarisas durante el periodo. En él figuraba una manda, por la cual Constanza de Villena fundaba y dotaba tres capellanías perpetuas que deberían cantarse, después de su muerte, en la iglesia del convento. Esas capellanías se nutrirían de las rentas de unos molinos de su propiedad, situados en el río Guadiela, junto al puente. La razón para fundar y dotar esas capellanías está, sin duda, relacionada con el hecho de que en el mismo testamento hubiera dispuesto que su cuerpo fuera enterrado en la misma iglesia del convento clariso. Sin embargo, parece ser que una vez otorgado, algo influyó en la primera voluntad de Constanza, que modificó la disposición relativa a esos molinos. Quizás la comunidad clarisa, sabedora de la responsabilidad que suponía el sostenimiento de esas capellanías en cumplimiento del testamento de Constanza, decidió manifestar a esta señora su disconformidad.

Sabemos que, cuando en 1377 se establecieron las capellanías reales dotadas en las rentas de las ollerías de Sevilla, el monasterio clariso fue dispensado por Enrique II de la obligación de dotar y desempeñar de manera efectiva las dos capellanías asignadas para que pudieran percibir la renta en moneda que llevaban aparejada por razón de limosna, sin necesidad de tomar providencia alguna para su desempeño efectivo.

90 1419, abril 12, Alcocer. Lope García y Gil Martínez, testamentarios de Teresa Díaz, viuda de Sancho Fernández de Cifuentes, venden en almoneda pública dos terceras partes de la viña de la senda del Galletero, propiedad de la fallecida, a Constanza de Villena, señora de Alcocer, para hacer frente a las mandas del testamento. AHN, Clero, 568/13. 
Es muy probable que la comunidad, acaso recelando de la introducción de nuevos capellanes, haya manifestado a Constanza su escasa disposición a hacerse cargo del desempeño de estas tres capellanías que había decidido fundar sobre las rentas de sus molinos. Constanza, tomando quizás en consideración la opinión al respecto de la comunidad clarisa, beneficiaria de esa su manda testamentaria, decidió anularla por un codicilo añadido en diciembre de 1428, dejando intacto todo lo demás. Sustituyó la manda anulada por otra más favorable a los intereses de la comunidad. En ella cedía llanamente la plena propiedad de los molinos, con el ruego de que las monjas tuvieran en adelante en cuenta a la generosa donante y a su familia en sus oraciones acostumbradas. La donación es efectiva desde el momento mismo de la concesión del codicilo, y en febrero de 1429 el franciscano fray Luis de Alcocer, como procurador del monasterio clariso, tomó posesión de esos molinos, situados junto al puente del Guadiela. ${ }^{91}$ Puede atestiguarse además que esos molinos procedían de la permuta que en 1402 Constanza de Villena había acordado con un propietario de Alcocer. ${ }^{92}$

Dejando a un lado las donaciones, parcas en este periodo, destaca el inicio de una importante línea dentro de la gestión económica de la comunidad, relativa a la afectación de importantes bienes del patrimonio monástico por censos a largo plazo, que se afianzará y proyectará hacia los tiempos modernos. En enero de 1438, la comunidad acordó dar al concejo de Cifuentes, en censo enfitéutico renovable de veinte en veinte años, buena parte, si no la totalidad, de los intereses en molinos que poseía en aquella villa. Ese censo fue expresamente autorizado por el ministro franciscano de Castilla, con objeto de emprender reparaciones de importancia en el monasterio y en los molinos del Guadiela. ${ }^{93}$ El otorgamiento revela que la comunidad quiere desligarse de los problemas que la gestión de esos bienes, relativamente alejados, le planteaba, al tiempo que aseguraba una renta fija por ellos, en un momento en que las perspectivas de rentas derivadas de la explotación de molinos no eran tan favorables.

${ }^{91}$ 1428, diciembre 17, Alcocer; y 1429, febrero 13, Alcocer. Codicilo del testamento de Constanza de Villena, viuda de micer Gómez de Albornoz, rectificando una manda de su testamento, para conceder a su muerte unos molinos en el Guadiela al monasterio de Santa Clara de Alcocer; y la subsiguiente toma de posesión de dichos molinos por parte de fray Luis de Alcocer, procurador del monasterio. AHN, Clero, 569/2.

92 1402, septiembre 16, Alcocer. Juan Martínez cambia su molino del Guadiela (consta de tres ruedas, dos de la capellanía de su hermana Catalina Martínez y la otra suya) a Constanza de Villena (viuda de micer Gómez de Albornoz) por una extensa serie de tierras dispersas en el término de Alcocer. Juan, obispo de Cuenca, como más alto custodio de los bienes de dicha capellania, aprueba y confirma el trueque. AHN, Clero, 568/9.

93 1437, agosto 4, Alcocer. Juan de Santana, ministro franciscano de Castilla, autoriza a las Clarisas de Alcocer para enajenar cualesquiera bienes de su monasterio, con objeto de sufragar ciertas reparaciones. El 13 de enero de 1438 - consta el instrumento en el mismo legajo - la comunidad clarisa concierta un censo perpetuo sobre sus molinos de la cuesta de Gárgoles de Arriba y de la Fuente Rodera, con el concejo de Cifuentes. AHN, Clero, legajo 1965, nº 16.

Hispania Sacra, LXV

132, julio-diciembre 2013, 563-601, ISSN: 0018-215X, doi: 10.3989/hs.2013.030 
Un testimonio excepcional permite conocer la situación económica difícil que el monasterio atravesó en los años de discordia civil del reinado de Enrique IV. En 1469, el papa Pablo II levantó la excomunión a dos antiguas monjas del monasterio de Alcocer, Constanza Pons y Constanza Gutiérrez, quienes habían abandonado el convento, debido a la penuria que en esos años sufría, para trasladarse al monasterio cisterciense de San Bernardo de Guadalajara. ${ }^{94}$ Tal parece que la mayor solidez patrimonial de la comunidad cisterciense de las bernardas brindaba un escenario más favorable en esos años de crisis.

Se ve que la general estabilidad en la evolución del patrimonio del monasterio de Alcocer no estuvo exenta de dificultades económicas a las que la comunidad debió hacer frente en coyunturas negativas. En consecuencia no faltaron algunas situaciones de penuria económica, pero la evolución constatable del patrimonio monástico fue, en general, de estabilidad. En las operaciones documentadas, pocas fueron de cierta trascendencia.

\section{REESTRUCTURACIÓN PATRIMONIAL (1483-1525)}

A partir del último tercio del siglo xv, se inicia un periodo muy interesante en la evolución del patrimonio del monasterio. Tal vez en consonancia con el proceso general de reactivación económica y renovación de estructuras que caracterizó a la Corona de Castilla desde la entronización de los Reyes Católicos, se observa en el patrimonio monástico una dirección que apunta hacia la reestructuración de sus bases económicas, en no pocos puntos y sobre nuevos presupuestos. Algunos de los recursos fundamentales, hasta entonces base de la supervivencia económica de la comunidad, se vieron de pronto en entredicho por la intromisión de factores exteriores, algunos conflictivos.

La comunidad tuvo que afrontar un proceso judicial para retener el cobro de la renta anual en el almojarifazgo de las ollerías de Sevilla, renta vinculada a la merced de las capellanías de 1377. Constan la importancia de esta renta y la dificultad que a veces concitaba su cobro. Entre los años de 1410 a 1416 fueron usurpadas todas por Gonzalo Tello, vecino de Sevilla, precisando los titulares de las rentas de reclamación judicial en firme para hacerse de nuevo con su cobro. ${ }^{95}$

\footnotetext{
94 «Absoluit ab excommunicatione Constantiam Pontii (Ponz) et Constantiam Gutterii (Gutiérrez), moniales monasterii S. Clarae uillae de Alcocer, ordinis eiusdem sanctae, Conchen. dioec., quae non inuitae a consanguineis et propinquis, absque licentia superiorum, extractae fuerant e dicto monasterio propter penuriam ipsius a recentibus bellis Castellae Legionisque productam, et translatae in monasterium S. Bernardi de Guadalajara, Cistercien. ordinis et Toletan. dioec.; ipsisque indulget ut in praefato coenobio Cistercien. et sub illius habitu permanere possint.» (el subrayado es nuestro): Bullarium Franciscanum, t. II (1455-1471): 775. Asís: Porziuncola.

${ }^{95}$ AHN, Clero, legajo 1967.
} 
Más tarde, fueron los mismos olleros, artesanos especializados en la elaboración de vajillas de barro y vidrio de las colaciones de Triana y Tablada, en Sevilla, quienes, ya en el reinado de los Reyes Católicos, se negaron a pagarla a sus titulares, como atestigua, desde 1488, el largo proceso judicial promovido contra ellos por iniciativa concertada y conjunta de los capellanes de la iglesia parroquial de Alcocer, los frailes franciscanos y las monjas clarisas de la villa, proceso que culminó en 1490 con la condena definitiva de los olleros rebeldes y la confirmación de la renta de las ollerías a sus legítimos propietarios. ${ }^{96}$ Subsistió quizás larvado este conflicto, pues sabemos que en fecha tan tardía como 1527 Carlos I hubo de exigir de nuevo a los olleros de Sevilla el cumplimiento de la sentencia de 1490 y el pago efectivo a sus titulares de los importes debidos por las rentas de ollerías. ${ }^{97}$

Otro litigio fue el entablado por la comunidad con unos recaudadores de las rentas de sal de las salinas de Atienza, por la percepción de la renta anual que el monasterio retenía en dichas salinas por concesión de Alfonso X. ${ }^{98}$ La sentencia, dictada en el verano de 1501, fue favorable al monasterio. ${ }^{99}$

Sobre la remodelación de las bases patrimoniales del monasterio, se puede mencionar en primer lugar la renovación de una renta en trigo que la comunidad cobraba en las tercias de Huete, de la cual no existe constancia anterior a 1483, fecha en la que los Reyes Católicos conceden a las monjas su cobro automático, sin necesidad de sacar libramiento cada año. Es revelador del momento económico el hecho de que el pago en metálico de las tasas anuales invalidara de facto el provecho que la comunidad percibía de esta renta basada en grano. ${ }^{100}$

Por lo demás, la comunidad interviene para adquirir, permutar o reformar rentas y recursos disfrutados desde antiguo, trocándolos por otras fuentes de ingresos renovadas. Es el caso del trueque de la renta de portazgos que la comunidad retenía desde la donación fundacional de doña Mayor Guillén. La parte de la renta que se cobraba en el Olmeda y Alaminos, lugares del término de Cifuentes, y en el mismo Cifuentes, su aldea el Val de San García y Palazuelos, luego de una larga negociación, fue entregada en 1492 por el monasterio a Juan de Silva, conde de Cifuentes, a trueco de una renta anual de algo más de 14.000 maravedíes situados en ciertas rentas realengas de Huete, cuyo disfrute tenía

${ }^{96}$ Archivo General de Simancas, Registro General del Sello: 1488-IX-30, f. 132; 1488-IX, f. 133; 1490-V-20, f. 284; 1490-V-25, f. 67; 1491-III-23, f. 362; AHN, Clero, legajo 1967.

${ }^{97}$ AHN, Clero, libro 4138, fols. 42v-43r; y Clero, legajo 1967. El desarrollo más por menudo de este proceso puede seguirse en: Martín Prieto, P. 2008.

${ }_{98}$ ARChVa, Pleitos Civiles, Quevedo (fenecidos), 2493-1.

${ }^{99}$ ARChVa, Reales Ejecutorias, 162/42 y 226/7.

100 «sy cada un anno oviesen de venir a sacar libramiento de los dichos diez cayzes de trigo, segund la poca cantidad dellos, se gastaria mas de lo que en ellos monta»: 1483, marzo 8, Madrid. Los Reyes Católicos conceden al monasterio de Santa Clara de Alcocer el cobro automático, sin necesidad de obtener cartas anuales de libramiento, de una renta de trigo en las alcabalas y tercias de Huete. AHN, Clero, 569/1.

Hispania Sacra, LXV

132, julio-diciembre 2013, 563-601, ISSN: 0018-215X, doi: 10.3989/hs.2013.030 
transferido el conde de Cifuentes. ${ }^{101} \mathrm{El}$ trueque da idea de la importancia relativa de la renta de portazgo en cuya equivalencia se desembolsaba esa suma, que en adelante percibirían de año en año las monjas, vinculada a los ingresos de alcabala de la ciudad de Huete, como consta por la renuncia pormenorizada de cada renta que, para mayor claridad, formalizó el conde de Cifuentes en $1500 .{ }^{102}$

Otras causas de remodelación patrimonial están relacionadas con la reforma que aquellos años se estaba introduciendo en los conventos franciscanos. En 1496 las monjas adquirieron por un precio de 130.000 maravedíes las dos capellanías que desde 1377 pertenecían al monasterio de San Francisco de Alcocer: liberaban de esta forma al convento franciscano de la carga que su sostenimiento suponía, a la vez que de la contradicción que para el impulso de la reforma y la reducción a la más estricta observancia representaba el cobro de la importante renta en metálico - procedente del almojarifazgo que se percibía de las ollerías de Sevilla - que el desempeño de las dos capellanías llevaba aparejado. ${ }^{103}$ Debe entenderse pues que, a partir de esa fecha, el monasterio comenzó a percibir las rentas de ollerías correspondientes a cuatro (antes tenía las de dos) de las siete capellanías fundadas por Enrique II. El traspaso de esas rentas fue objeto de detallada y formal aprobación y confirmación por parte de Carlos I en $1520^{104}$ y de la Santa Sede en $1525 .{ }^{105}$

Las monjas compraron otra renta a un convento franciscano motivo de la introducción de la observancia. Fue una de 3000 maravedíes que el convento de San Francisco de Huete tenía en las tercias de esa ciudad, operación concluida antes de $1502 .{ }^{106}$ Este convento, impulsado por la misma necesidad de reforma,

101 1492, enero 27, Cifuentes. El monasterio de Santa Clara de Alcocer permuta con el conde de Cifuentes sus rentas en el portazgo de Cifuentes (y Olmeda del Extremo) por una renta de 14.130 maravedíes situados en la ciudad de Huete. AHN, Clero, legajo 1966.

102 1500, diciembre 10. Juan de Silva, conde de Cifuentes, renuncia en el monasterio de Santa Clara de Alcocer sus rentas sobre las alcabalas del pan y de la carne en Huete. AHN, Clero, 569/4.

103 1496, agosto 5, Alcocer. El convento franciscano de San Miguel del Monte de Alcocer vende al monasterio de Santa Clara de la misma villa, por 130.000 maravedíes, la renta en las ollerías de Triana y Tablada asociada al desempeño de dos capellanías, cuyo cargo asimismo le traspasa. AMA, libro A1, fols. 189r-193r.

104 1520, abril 28, La Coruña. Carlos I aprueba y confirma el traspaso de dos capellanías perpetuas del monasterio de San Francisco de San Miguel del Monte de Alcocer al monasterio de Santa Clara de Alcocer. AHN, Clero, libro 4138, fol. 37r. Hay un traslado en AMA, libro A1, fols. 195r-196r.

105 1525, diciembre 18, Toledo. El cardenal Juan, legado de Clemente VII, confirma en nombre de la Santa Sede el traslado de las capellanías del monasterio franciscano de San Miguel del Monte al monasterio de Santa Clara de Alcocer. AHN, Clero, legajo 1967, y libro 4140, fols. 4r-4v.

106 1502, octubre, 28, Huete. Julián de la Puerta, como procurador del monasterio de Santa Clara de Alcocer, presenta testigos para acreditar la posesión, por parte del monasterio de San Francisco de Huete, de una renta de 3000 maravedíes en las tercias de Huete, que recientemente había sido adquirida por el monasterio clariso de Alcocer. AHN, Clero, legajo 1968, nº 14. 
vendió a las monjas de Alcocer en 1505 una renta de 36 fanegas de sal de las salinas de Belinchón, que, por donación regia, venía gozando desde 1345. ${ }^{107}$

Esta última compra tendrá efectos casi inmediatos en la reestructuración del patrimonio monástico. Cuando las monjas aseguraron el cobro de esa renta de sal situada en las salinas de Belinchón, observaron que la renta de sal que, de antaño, ellas mismas tenían en las salinas de Atienza, sería en adelante inútil, razón por la cual decidieron deshacerse de ella, buscando una contrapartida de mayor interés para su patrimonio. Es una ironía que, poco tiempo antes la comunidad pleiteó con éxito ante la real audiencia de Valladolid por retener el cobro de esa misma renta de la que en este momento decidió deshacerse. La comunidad ofreció revertir la renta a la corona, demandando de su titular una contraprestación en las tercias reales del partido de Zorita. Cuando acabó la operación, tuvo por efecto la incorporación en 1512 al patrimonio del monasterio clariso de una importante renta anual en trigo situada en las tercias reales de Fuentelaencina, Auñón y Berninches, lugares del partido de Zorita. Parece que esto fue de mayor provecho para el monasterio que la sal de Atienza, en cuya equivalencia le fue entregada. ${ }^{108}$

En este periodo es necesario mencionar también la continuación de la política de arrendamientos a largo plazo y entrega en censo de importantes bienes del patrimonio monástico a cambio de la segura compensación de rentas fijas, ya iniciada en el periodo inmediatamente anterior. Será uno de los fundamentos de la economía monástica durante el siglo XVI. Así, en 1496 la comunidad entregó en censo enfitéutico su molino de aceite, situado dentro de la villa de Alcocer, por una renta anual fija en aceite. ${ }^{109}$

La dotación fundacional de 1260 ha supuesto, para nuestro análisis de la evolución del patrimonio monástico, el punto de partida. El apeamiento de 1519 se puede considerar el punto idóneo de llegada. ${ }^{110}$ En esta fecha la comunidad clarisa acordó reclamar de la autoridad municipal de Alcocer la elaboración de

107 1505, junio 29, 30, y julio 1, Huete. El monasterio de San Francisco de Huete, tras obtener la pertinente licencia del custodio de Murcia, renuncia la renta de 36 fanegas de sal en las salinas de Belinchón en el convento clariso de Alcocer, que había compensado previamente al monasterio de Huete con dineros empleados en la restauración de edificios. AHN, Clero, 569/6.

108 1512, abril 24, Burgos. Juana I recibe la renuncia efectuada por el convento de Clarisas de Alcocer, de una renta de sal en las salinas de Atienza, concedida por Alfonso X en 1274, a cambio de una renta en las tercias que la Corona retenía en Fuentelaencina, Auñón y Berninches, aldeas de la villa de Zorita. AHN, Clero, 569/8.

109 1496, agosto 7, Alcocer. El monasterio de Santa Clara de Alcocer da a censo perpetuo al concejo de la villa un molino de aceite en régimen de exclusividad o monopolio de hecho, con tres condiciones. AHN, Clero, legajo 1967, $\mathrm{n}^{\circ} 1$.

110 1519, diciembre 2, Alcocer. Apeamiento de las tierras que el monasterio de Santa Clara de Alcocer tenía en el término de la villa y sus inmediaciones. AHN, Clero, libro 4140, fols. 122r-132v.

Hispania Sacra, LXV

132, julio-diciembre 2013, 563-601, ISSN: 0018-215X, doi: 10.3989/hs.2013.030 
un apeamiento general de cuantas propiedades rústicas poseía el monasterio en el término de la villa. La atenta consideración del documento permite constatar que, para buena parte de las tierras allí relacionadas, no hay constancia documental del momento en que se incorporaron al patrimonio monástico. Hay que conformarse con saber que, en 1519, eran del monasterio, pero cabe verosímilmente suponer que la mayor parte de estas tierras llegaron a integrarse en el patrimonio de la comunidad durante los siglos anteriores, sin que quepa esperar alcanzar seguridad sobre el momento preciso en que las monjas entraron a poseer cada una de ellas. En todo caso, la imagen que el apeamiento de 1519 proporciona es de cierta abundancia: con 69 propiedades rústicas relacionadas, el monasterio clariso era sin duda uno de los mayores propietarios agrarios de Alcocer, si no el mayor.

Sabemos que la comunidad disponía al menos de otro apeamiento anterior. ${ }^{111}$ La verdadera razón que mueve a las monjas a solicitar la elaboración de este nuevo documento de 1519 está influida por la necesidad de afirmar sus derechos sobre algunas tierras en litigio. Así, en el texto del apeamiento se recogen las diligencias efectuadas por los apeadores para delimitar con claridad los límites de algunas fincas propiedad del monasterio, y en algunos casos no claros se ordena a quienes las ocupaban o laboraban que regularizaran su situación como arrendatarios determinando con el convento las condiciones en que las venían explotando. Como resultado de estas diligencias, la comunidad denunció la nueva edificación - no autorizada por el propietario - de un batán por parte de uno de los censatarios del monasterio.

Desde 1451, las monjas habían cedido a un particular, vecino de Alcocer, probablemente en régimen de censo enfitéutico, un solar para edificar un batán junto al Riato, en el término de San Miguel. En 1481 el hijo del primer tomador del censo renovó con la comunidad los términos del acuerdo. Más tarde, el nieto abrió nuevo caz y edificó un batán nuevo cerca del antiguo: este es el batán descubierto durante las diligencias del apeamiento de 1519 y cuya construcción las monjas entendían infringía los términos del contrato concertado con el abuelo y ratificado con el nieto. El pleito se dirimió por sentencia arbitral en $1520 .{ }^{112}$

Reajustando las condiciones del censo, las monjas permitieron al propietario seguir disfrutando del batán nuevo, procediendo al mismo tiempo a un intercambio de parcelas: la huerta asociada al batán viejo pasaría a ser gestionada por la comunidad, y a cambio el censatario recibiría una finca nueva, más cercana al batán nuevo. De todo este episodio pueden anotarse algunas modificaciones

${ }^{111}$ La existencia de ese apeamiento más antiguo, que por desgracia no ha llegado hasta nosotros, queda revelada en el mismo texto del apeamiento de 1519.

112 1520, abril 12 y 13, Alcocer. Sentencia arbitral en la disputa entre el monasterio de Santa Clara de Alcocer y el bachiller Moreno sobre un batán en el Riato. AHN, Clero, libro 4140, fols. 88r-98r. 
de relevancia en el patrimonio del monasterio, referentes a la entrega en censo, desde mediados del siglo $\mathrm{xv}$, de un terreno propio del término originario de San Miguel, acondicionado para un aprovechamiento industrial de los recursos hídricos.

A pesar de la insuficiencia de la documentación conservada hasta nuestros días para un seguimiento completo de la evolución patrimonial, los indicios disponibles permiten caracterizar esta última etapa, a caballo de los siglos XV y XVI, como de transición. Nuevamente se reestructuraron las bases patrimoniales del convento, debido a factores de gestión, ligados a la coyuntura económica general, y a otros relacionados con la reasignación de bienes monásticos procedentes de otras comunidades religiosas de la primera orden franciscana afectada por la reforma.

\section{CONCLUSIONES}

El seguimiento pormenorizado del proceso de constitución y evolución del patrimonio del monasterio clariso de Alcocer permite derivar algunas consecuencias de interés sobre modalidades de integración y gestión de los bienes, típicas de comunidades religiosas, sobre el telón de fondo de la coyuntura económica general.

El impulso fundacional fue concertado por la corona castellana con la estirpe noble de los Guzmán, y se personificó en la especial relación entre Alfonso X y doña Mayor Guillén. Buena parte de los bienes y derechos sobre los que se fundaron las bases materiales para la vida futura de la comunidad clarisa proceden del señorío creado para esta última en 1255, y en último término, del realengo.

Cuando la dinastía de la fundadora se deshizo de la villa de Alcocer, sus sucesivos señores, sin llegar a desentenderse por entero de la suerte del monasterio, fueron mucho menos activos en la protección de sus intereses. Esto exigió a la comunidad clarisa emplearse a fondo para poner en pie una política propia de gestión económica de su patrimonio, en buena medida independiente de otras instancias, si bien contó, en algunos momentos, con la ayuda de la corona y de los señores de la villa. Las décadas centrales del siglo XIV marcan un punto bajo, y quizás también de máxima autonomía - o desamparo- en la evolución del patrimonio monástico, coincidiendo con los desórdenes asociados a la guerra en la que se resolvió el reinado de Pedro I.

La entronización de la nueva realeza Trastámara, vinculada familiarmente a los Guzmán, proporciona un nuevo impulso de refundación, sobre nuevas bases, del patrimonio monástico. Tanto la dotación de nuevas rentas como el traslado de la comunidad clarisa a un nuevo monasterio emplazado en el interior de la 
villa de Alcocer son iniciativas relevantes en las que la corona tiene parte decisiva. La evolución del patrimonio monástico a lo largo del siglo xv es estable y segura, aunque a veces tienda a un cierto estancamiento. A finales de esa centuria, y entrando ya en el siglo XVI, hay una renovación o reestructuración del patrimonio, acelerada en parte por la necesidad de contribuir a la reforma de otros monasterios franciscanos masculinos de la región.

En su conjunto, el análisis de la evolución del patrimonio de esta institución religiosa revela una alternancia de momentos de mediano esplendor con otros de franco declive; dicha alternancia se puede poner en relación tanto con la coyuntura económica general en la Castilla de la época, como con la suerte vivida por otras comunidades religiosas, masculinas y femeninas, de cada momento, para mejor percibir las líneas de coincidencia y los hitos de singularidad del caso particular del patrimonio de las clarisas de Alcocer, cuya conformación estructural - en la que cabe percibir su mayor continuidad - habrá sido su dependencia de la economía rural de Alcocer, así como la renovación intermitente de la protección de la corona castellana sobre ese su «real monasterio».

\section{FUENTES}

España, Archivo General de Simancas (AGS), Registro General del Sello (RGS), registros de los años: 1488, 1490, 1491.

España, Archivo Histórico Nacional, Madrid (AHN). Clero: carpetas de pergaminos nos. 566-569; libros nos. 4138, 4140; legajos en papel nos. 1965-1968; Sellos: carpetas nos. 55.

España, Archivo Municipal de Alcocer (Guadalajara) (AMA), libro A1.

España, Archivo de la Real Chancillería de Valladolid (ARCV), Pleitos Civiles, Quevedo (fenecidos), 2491-1; Reales Ejecutorias: nos. 162/42, 226/7.

Portugal, Lisboa, Arquivo da Torre do Tombo (ATT), Leitura Nova, Livro $1^{\circ}$ de Extras, MF 2471.

\section{BIBLIOGRAFÍA}

Bois, G. 1976. Crise du féodalisme. París: Fondation Nationale de Sciences Politiques.

Castro, M. 1982. El Real Monasterio de Santa Clara de Palencia y los Enríquez, Almirantes de Castilla. Palencia: Diputación Provincial.

Castro Garrido, A. 1987. Documentación del monasterio de las Huelgas de Burgos (1307-1321). Burgos: Ediciones JM Garrido Garrido.

Cortes I. Cortes de los antiguos reinos de León y Castilla, t. I. 1881. Madrid: Real Academia de la Historia.

Crónicas I. 1953. Crónicas de los reyes de Castilla, t. I (BAE LXVI). Madrid: Real Academia de la Historia. 
Font Tullot, I. 1988. Historia del clima de España. Cambios climáticos y sus causas. Madrid: Instituto Nacional de Meteorología.

Garibay, E. 1628. Compendio historial de las chronica y universal historia de todos los reynos de España, t. II. Barcelona: Sebastián de Cormellas.

Layna Serrano, F. 1979. Historia de Cifuentes. Guadalajara: Diputación Provincial ( $2^{\mathrm{a}}$ ed).

Martín Prieto, P. 2002-2003. «Origen, evolución y destino del señorío creado para la descendencia de Alfonso X de Castilla y Mayor Guillén de Guzmán (1255-1312)». Temas Medievales 11: 219-240.

Martín Prieto, P. 2005 [1]. «La fundación del monasterio de Santa Clara de Alcocer (1252-1260)». Hispania Sacra 115: 227-241.

Martín Prieto, P. 2005 [2]. «Los prolegómenos de la gran crisis bajomedieval en Castilla (c. 1250-c. 1350): el caso de Alcocer». Cuadernos de Investigación Histórica 22: 291-311.

Martín Prieto, P. 2006. «Aportación al estudio del molino hidráulico en la Castilla medieval: los molinos del monasterio de Santa Clara de Alcocer». Hispania 224: 833-850.

Martín Prieto, P. 2007. «Sobre la promoción regia de la orden franciscana en la Corona de Castilla durante el primer reinado Trastámara». Hispania Sacra 119: 51-83.

Martín Prieto, P. 2008. «Los olleros de Sevilla contra los capellanes y conventos de Alcocer: un pleito del siglo XV». Historia. Instituciones. Documentos 35: 291-307.

Martín Prieto, P. 2011. «De los Albornoz a los Mendoza: la transmisión del estado señorial del Infantado de Huete en la Baja Edad Media». En la España medieval 34: 229-247.

Moreta Velayos, S. 1974. Rentas monásticas en Castilla: problemas de método. Salamanca: Universidad.

Moreta Velayos, S. 1978. Malhechores-feudales: violencia, antagonismos y alianzas de clases en Castilla, siglos XIII-XIV. Madrid: Cátedra.

Moxó, S. 1990. «Época de Alfonso X», en R. Menéndez Pidal (ed.), Historia de España. XIII-1. La expansión peninsular y mediterránea (1212-1350). La Corona de Castilla. Madrid: Espasa-Calpe.

Muñoz Fernández, A. 1994. «Las clarisas en Castilla la Nueva. Apuntes para un modelo de implantación regional de las órdenes mendicantes femeninas franciscanas (1250-1600)», en Las clarisas en España y Portugal. Actas del Congreso Internacional de Salamanca, 20-25 septiembre 1993, t. II-1: 455-472. Madrid: Archivo Ibero-Americano.

Ortega, M. 1740. Chronica de la Santa Provincia de Cartagena, t. I. Murcia: Francisco López Mesnier.

Pérez Celada, J. A. 1998. «Algunas consideraciones sobre la conducta de los monjes cluniacenses ibéricos en la Baja Edad Media», en VIII Semana de Estudios Medievales (Nájera): 294-295. Logroño: Instituto de Estudios Riojanos.

Pretel Marín, A. y Rodríguez Llopis, M. 1998. El señorío de Villena en el siglo XIV. Albacete: Diputación Provincial. 
Ruiz, T. 1981. Sociedad y poder real en Castilla (Burgos en la Baja Edad Media). Barcelona: Ariel.

Sánchez Moguel, A. 1893. «Doña Blanca de Portugal». Boletín de la Real Academia de la Historia 23: 538-560.

Villalba Ruiz de Toledo, F. J. 1989. «El monasterio de Santa Clara de Alcocer y su conexión con la monarquía castellana (siglos XIII-Xv)». Wad-al-.Hayara 17: 319-324.

Wadding, L. 1932. Annales Minorum seu Trium Ordinum a Sancto Francisco Institutorum, t. IX (1377-1417). Quaracchi: Collegio San Bonaventura. 